\title{
DIAGNÓSTICO DA OCORRÊNCIA DE CUPINS XILÓFAGOS EM ÁRVORES URBANAS DO BAIRRO DE HIGIENÓPOLIS, NA CIDADE DE SÃO PAULO
}

\author{
RAQUEL DIAS DE AGUIAR MORAES AMARAL
}

Dissertação apresentada à Escola Superior de Agricultura "Luiz de Queiroz", Universidade de São Paulo, para obtenção do título de Mestre em Recursos Florestais, Área de Concentração: Recursos Florestais, com opção em Tecnologia de Produtos Florestais.

PIRACICABA

Estado de São Paulo - Brasil

Janeiro - 2002 


\title{
DIAGNÓSTICO DA OCORRÊNCIA DE CUPINS XILÓFAGOS EM ÁRVORES URBANAS DO BAIRRO DE HIGIENÓPOLIS, NA CIDADE DE SÃO PAULO
}

\author{
RAQUEL DIAS DE AGUIAR MORAES AMARAL
}

Engenheiro Agrônomo

ORIENTADOR: Prof. Dr. Marcio Augusto Rabelo Nahuz

Dissertação apresentada à Escola Superior de Agricultura "Luiz de Queiroz", Universidade de São Paulo, para obtenção do título de Mestre em Recursos Florestais, Área de Concentração: Recursos Florestais, com opção em Tecnologia de Produtos Florestais.

PIRACICABA

Estado de São Paulo - Brasil

Janeiro - 2002 


\section{Dados Internacionais de Catalogação na Publicação (CIP)} DIVISÃO DE BIBLIOTECA E DOCUMENTAÇÃO - ESALQ/USP

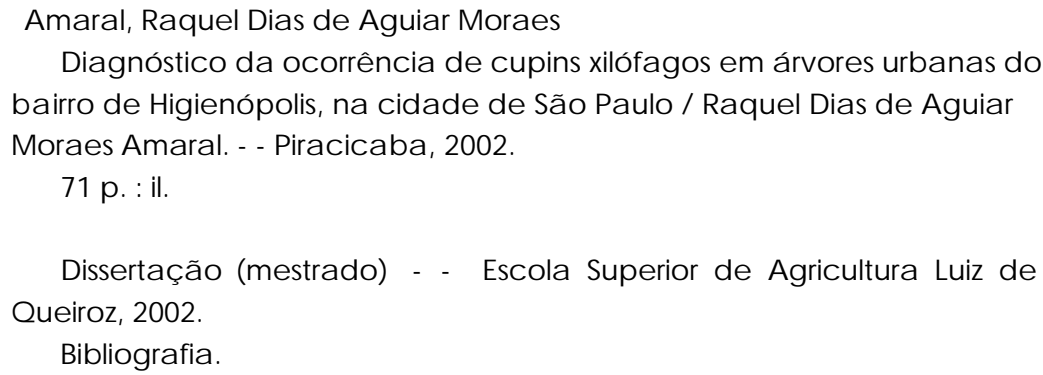

CDD 634.96736 
Dedico

aos meus pais, Paulo e Regina, por terem me ensinado a buscar o conhecimento. 


\section{AGRADECIMENTOS}

Ao meu companheiro Guilherme pela compreensão e auxílio.

Ao Dr. Marcio, sem sua orientação não poderia ter iniciado e concluído o mestrado que muito almejava.

Ao Dr. Lelis, por quem tenho estima e admiração. Sob sua orientação iniciei o trabalho com os cupins, tive a oportunidade de publicar minha primeira pesquisa e desenvolver as idéias preliminares deste projeto de mestrado.

Ao colega Rubens por todo o apoio e muita paciência.

Grata ao meu chefe Gonzalo que sempre me apoiou neste projeto.

Agradeço, pela força e questionamentos, à amiga Lígia, ao Sérgio, Beatriz e Antônio, meu consultor de todas as horas.

Aos colegas que tiveram participação nesta minha empreitada, os meus sinceros agradecimentos; Prof. Dr. Mário Tomazello Filho, Dr. ${ }^{a}$ Leide Yassuco Takahashi, Dr. Reginaldo Constantino, Dr. Paulo Renato, Ricardo Cabreira, Luiz Reis e Gisleine, Adriana, Cássia Fellet, Ana Cândida e Luciana Gomes Castro. Aos funcionários da Seção de Tecnologia de Fabricação da Divisão de Mecânica e Eletricidade do IPT, que fizeram o Resistógrafo ${ }^{\circledR}$ "renascer". Aos técnicos do Laboratório de Entomologia; Agberto Almeida da Silva, João Lindomar Faria e Manoel Pereira, que me auxiliaram na execução dos trabalhos de campo.

À empresa Base aerofotogrametria e projetos S.A., que, muito gentilmente, nos cedeu a fotografia aérea do bairro de Higienópolis. 


\section{SUMÁRIO}

Página

LISTA DE FIGURAS......................................................................... vii

LISTA DE TABELAS ............................................................................... ix

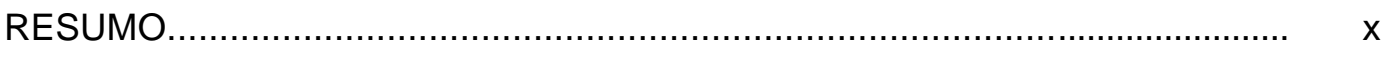

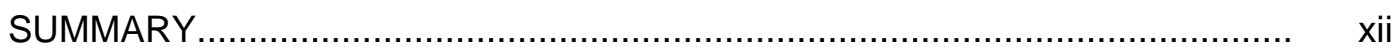

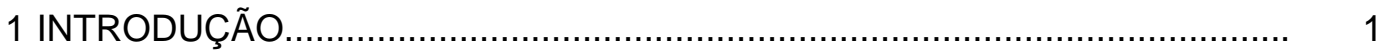

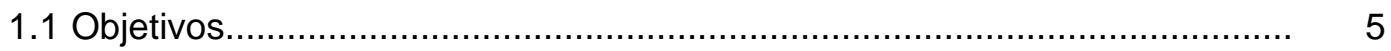

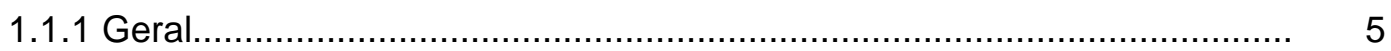

1.1.2 Específicos................................................................................. 5

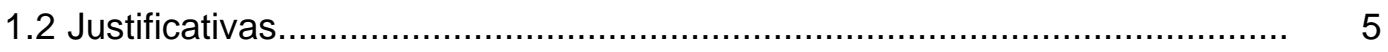

2 REVISÃO DE LITERATURA...................................................................

2.1 Ocorrências de cupins-xilófagos................................................................... 7

2.2 Avaliação não-destrutiva..................................................................... 14

3 MATERIAL E MÉTODOS................................................................... 16

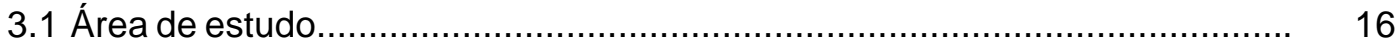

3.2 Seleção das árvores........................................................................... 17

3.3 Diagnóstico das árvores......................................................................... 17

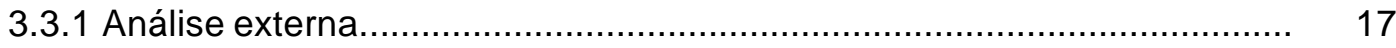

3.3.2 Prospecção e Análise interna................................................................ 18 
3.4 Determinação de classes de decaimento da resistência da madeira na 20 prospecção interna

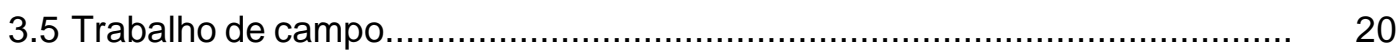

3.6 Correlação entre os atributos dos indicadores externos (A, B e C) com os 22 atributos dos indicadores internos (D e E) das árvores.

4 RESULTADOS e DISCUSSÃO........................................................ 24

4.1 Censo das árvores no bairro de Higienópolis............................................ 24

4.2 Presença de cupins nas árvores.......................................................... $\quad 25$

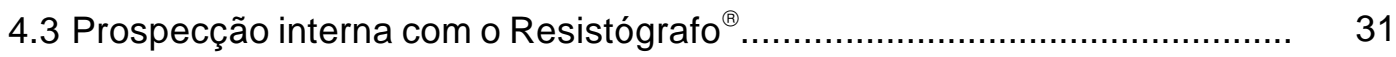

4.3.1 Intensidades de decaimento.............................................................. 31

4.4 Análise interna com o Boroscópio........................................................... 35

4.5 Correlação entre os atributos dos indicadores externos e a ocorrência 36 interna de cupins.

4.5.1 Modelos completos para Prospecção Interna e Análise 36 Interna.

4.5.2 Processo de simulação............................................................................. $\quad 37$

4.5.3 Modelo simplificado para a Prospecção Interna.................................... 37

4.5.4 Modelo simplificado para a Análise Interna............................................. 38

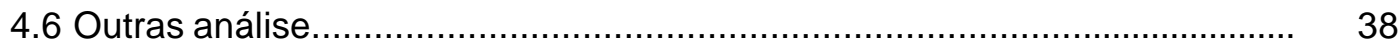

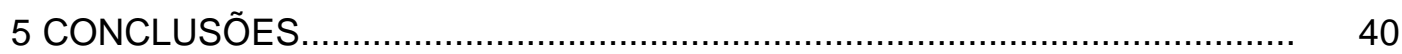

5.1 Conclusões adicionais e recomendações............................................... 41

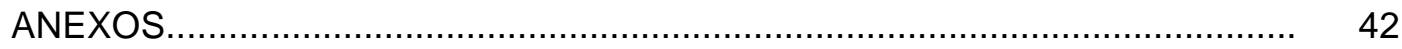

REFERÊNCIAS BIBLIOGRÁFICAS..................................................... 66 


\section{LISTA DE FIGURAS}

Página

1 Freqüencia das árvores pesquisadas......................................................... $\quad 25$

2 Presença de cupins nas árvores............................................................. 26

3 Gráfico da prospecção interna da árvore alfeneiro, registrada com o número 32 11, na Tabela 1

4 Gráfico da prospecção interna da árvore sibipiruna, registrada com o 33 número 02, na Tabela 1

5 Gráfico da prospecção interna da árvore alfeneiro, registrada com o número 34 32, na Tabela 1

6 Mapa do bairro de Higienópolis

7 Túneis de cupins-subterrâneos em reentrâncias de Caesalpinia 44 peltophoroides.

8 Calçamento inadequado

9 Teste com o equipamento Resistógrafo ${ }^{\circledR}$

10 Árvore alfeneiro, registrada com o número 10, na Tabela 1.

11 Árvore alfeneiro, registrada com o número 04, na Tabela 1.

12 Árvore sibipiruna, registrada com o número 34, na Tabela 1 
14 Árvore mamorana, registrada com o número 25, na Tabela 1................... 49

15 Árvore sibipiruna, registrada com o número 01, na Tabela $1 \ldots \ldots \ldots \ldots \ldots \ldots \ldots . . . \ldots \ldots$

16 Árvore quaresmeira, registrada com o número 13, na Tabela 1................ 50

17 Árvore tipuana, registrada com o número 36, na Tabela 1....................... 51

18 Árvore alfeneiro, registrada com o número 08, na Tabela 1.................... 51

19 Árvore espatódea, registrada com o número 29, na Tabela 1................... 52

20 Árvore alfeneiro, registrada com o número 14, na Tabela 1..................... 53

21 Árvore alfeneiro, registrada com o número 18, na Tabela 1...................... 53

22 Árvore sibipiruna, registrada com o número 23, na Tabela 1.................... 54

23 Árvore tipuana, registrada com o número 33, na Tabela 1........................ 54

24 Árvore ficus, registrada com o número 12, na Tabela 1.......................... 55 


\section{LISTA DE TABELAS}

Página

1 Registro do diagnóstico das árvores......

2 Matriz indicadora 0 e 1

3 Matriz de correlação entre as variáveis independentes

4 Resultados da análise de componentes principais

5 Autovalores e variâncias dos componentes principais.

6 Resultado da análise de regressão dos coeficientes dos componentes principais da Prospecção Interna

7 Resultado da análise de regressão dos coeficientes dos componentes principais da Análise Interna.

8 Coeficientes para o modelo completo da Prospecção Interna

9 Coeficientes para o modelo completo da Análise Interna. 


\title{
DIAGNÓSTICO DA OCORRÊNCIA DE CUPINS XILÓFAGOS EM ÁRVORES URBANAS DO BAIRRO DE HIGIENÓPOLIS, NA CIDADE DE SÃO PAULO
}

\author{
Autora: RAQUEL DIAS DE AGUIAR MORAES AMARAL \\ Orientador: Prof. Dr. MARCIO AUGUSTO RABELO NAHUZ
}

\section{RESUMO}

O problema de cupins xilófagos observado nas edificações e prédios históricos, localizados na cidade de São Paulo, Brasil, não se limita apenas a estas estruturas, mas também às árvores que, além de serem atacadas, podem constituir-se de abrigo para estes insetos de hábito subterrâneo. O fato destes cupins apresentarem grande capacidade de dispersão, pode comprometer a sanidade biológica de outras árvores e também das edificações. Como no Brasil verifica-se a falta de critérios para diagnosticar corretamente a infestação nas árvores, este trabalho têm como objetivos, verificar a existência de uma correlação de alguns indicadores externos, com a ocorrência interna de cupins xilófagos em árvores urbanas, além de estimar a intensidade dessa infestação por meio de uma avaliação não-destrutiva. Foram diagnosticadas 49 árvores por meio da análise externa da presença de vestígios ou túneis de cupins na casca e entre casca e no solo junto àbase da árvore, das condições gerais e do local em que a árvore encontrava-se plantada. Além da análise externa, também foi realizada a prospecção interna do tronco com a utilização de um método não-destrutivo para verificar a intensidade do possível ataque causado pelos cupins xilófagos. 
Dos indivíduos inspecionados, 28,60\% apresentaram cupins vivos ou sinais destes insetos e a espécie encontrada foi Coptotermes havilandi Holmgren. Também foi observada a existência de uma correlação entre um dos indicadores da análise externa com a análise interna em $50 \%$ dos casos. Quando observado o indicador análise externa do tronco, nos graus de intensidade "ataque" e "ataque intenso", a perda de resistência da madeira, na classificação "decaimento intenso", representava que a sanidade biológica interna, havia sido comprometida pela ação dos cupins. 


\title{
DIAGNOSIS OF THE OCCURRENCE OF XYLOPHAGOUS TERMITES IN URBAN TREES OF A NEIGHBORHOOD OF SÃO PAULO CITY, BRAZIL.
}

\author{
Author: RAQUEL DIAS DE AGUIAR MORAES AMARAL \\ Adviser: Prof. Dr. MARCIO AUGUSTO RABELO NAHUZ
}

\section{SUMMARY}

The problem of xylophagous termites in the edifications and historical buildings of the city of São Paulo, Brazil, is not confined to these structures, but also to the trees which, besides being attacked can shelter these insects of subterranean habit. The dispersion capacity of these termites can jeopardize the biological sanity of other trees and also of buildings. As in Brazil there is a lack of criteria to correctly detect and verify termite infestation in trees, this work aims at determining the existence of a correlation between external indicators and the internal presence of xylophagous termites in urban trees, in addition to estimating the intensity of the termite infestation by means of nondestructive evaluation. Forty-nine trees were examined for external signs of the presence of termites, tunnels or vestiges in the bark or inner bark of the trees, in the soil around the base of the trees, the general conditions and the site where the trees were planted. In addition to the external analysis, an internal search in the trunk was carried out through a non-destructive method to estimate the intensity of the possible attack by termites. 
Of the trees inspected, $28,60 \%$ presented live termites or signs that indicated their presence, and the species found was Coptotermes havilandi Holmgren. An existing correlation between one indicator of the external analysis and the internal analysis was detected in $50 \%$ of the cases. When the indicator at external analysis of the trunk with the intensity degrees "attack" and "intense attack" was detected, the "intense decline" loss on wood strength meant that interns of internal biological sanity, the tree had been affected by termite action. 


\section{INTRODUÇÃO}

Os cupins ou térmitas constituem a ordem Isoptera, são insetos sociais e predominantemente tropicais. Portanto, climas quentes e úmidos como os do Brasil Ihes são favoráveis. Atualmente, estão descritas no mundo 2.861 espécies de cupins das quais 287 ocorrem no Brasil e pertencem a cinco famílias (Constantino, 2002).

Dados da literatura indicam que é relativamente pequena a proporção das espécies consideradas como pragas em relação ao número total das espécies de cupins de uma determinada região (Zorzenon \& Potenza, 1998). No entanto, em diversas regiões do mundo, os cupins xilófagos estão entre aqueles insetos responsáveis por grande parte dos prejuízos advindos da deterioração biológica da madeira. Esse problema refere-se, em muitos casos, àsáreas urbanas, uma vez que nelas concentra-se grande quantidade de madeira, muitas vezes susceptível e sem nenhum tratamento preventivo, em uso pelo homem.

A fonte de alimentação dos cupins é a matéria orgânica vegetal. As espécies xilófagas atacam a madeira mesmo quando esta se encontra em ótimas condições de sanidade, enquanto que outras espécies somente a utilizam, ou outro material vegetal, quando já se encontra com certo grau de deterioração causada por fungos (Oliveira et al., 1986).

De modo geral são duas as espécies de cupins xilófagos causadoras de prejuízos e presentes nas construções da área urbana da região sudeste do Brasil: Coptotermes havilandi da família Rhinotermitidae, conhecido como cupim-subterrâneo e considerado a principal praga da região sudeste do Brasil e Cryptotermes brevis da família Kalotermitidae, conhecido como cupim-de-madeira-seca, cosmopolita e a segunda pior praga do sudeste brasileiro (Zorzenon \& Potenza, 1998). 
As colônias dos cupins-de-madeira-seca localizam-se inteiramente dentro da madeira que consomem como alimento, sem a necessidade de contato com o solo (Fontes \& Araujo, 1999). Portanto, o seu ataque caracteriza-se por ser um problema restrito às peças de madeira infestadas. São encontrados em todos os tipos de edificações e seu ataque ocorre em madeiras com baixo teor de umidade, localizadas tanto nas estruturas quanto em móveis e peças avulsas. Na natureza ocorrem tanto em árvores em pé, vivas ou mortas, como em troncos caídos em decomposição (Zorzenon \& Potenza, 1998).

Os cupins-subterrâneos, por sua vez, apresentam ninhos mais elaborados que se desenvolvem preferencialmente no solo, interno ou externo à edificação, em madeiras em contato com o solo, em espaços que possam existir no interior das edificações, ou ainda em árvores, onde a umidade do solo, entre outros fatores, facilita a sua instalação (Lelis, 1985 e Leonardo et al., 1999).

Esses cupins apresentam grande capacidade de dispersão e a ligação entre a colônia e a fonte de alimento é feita por meio de túneis construídos pelos insetos. $\mathrm{O}$ ataque desses cupins é generalizado e não se limita à madeira e seus derivados. Outros materiais tais como tecidos, plásticos, borracha, couro, tijolos de barro, gesso e revestimentos de cabos elétricos também podem ser intensamente atacados por esses insetos, que podem ou não ingeri-los, no entanto não são utilizados como alimento, sendo eliminados sem serem digeridos (Zorzenon \& Potenza, 1998).

De acordo com as informações geradas pelo Laboratório de Entomologia do I.P.T, os problemas diagnosticados nas edificações tratam-se, na maioria dos casos, de infestações por Coptotermes havilandi, espécie de cupim originária do sudeste da Ásia, que se adaptou muito bem às condições urbanas do sul do Brasil, principalmente dos grandes centros urbanos como São Paulo e Rio de Janeiro.

Com base nos levantamentos realizados pelo I.P.T., estimou-se em US\$ 3.350 milhões o valor necessário para controlar problemas de cupins em 240 edificações da capital paulista, sendo que Coptotermes havilandi era a principal espécie de cupim, presente em $85 \%$ dos casos (Lelis, 1994). 
Além das edificações, observa-se também uma grande infestação de árvores por cupins-subterrâneos, que, pela dispersão subterrânea ou pela revoada, época do acasalamento, propaga o ataque termítico às edificações (Fontes, 1998, Henderson et al., 1995 e Osbrink et al., 1999). As árvores constituem um foco para a reinfestação de edificações tratadas, embora o inverso também possa ocorrer (Fontes, 1998). Segundo o mesmo autor, estes cupins são responsáveis por grandes prejuízos à arborização urbana, e as árvores constituem um abrigo para estes insetos.

Zorzenon \& Potenza (1998) relatam que árvores comuns na cidade de São Paulo como sibipiruna, jacarandá-mimoso, quaresmeira, acácia, ipê, paineira, tipuana e outras, podem ser infestadas por cupins, o que pode acarretar sua morte.

No Brasil, não existem publicações referentes aos prejuízos econômicos causados pelos cupins xilófagos à arborização urbana, contudo, em New Orleans, Louisiana, nos Estados Unidos, a espécie Coptotermes formosanus Shiraki, é responsável por um dano anual à arborização urbana de aproximadamente US\$ 6 milhões (Freytag \& Cink, 2001).

Atualmente, quando ocorre a suspeita de uma infestação em árvores, verificase a falta de critérios para diagnosticar corretamente o problema, dificultando a tomada de decisões, seja quanto às medidas de controle aplicáveis, seja quanto à remoção ou não da árvore.

No momento presente, a análise do ataque de cupins às árvores é realizada apenas pelo exame na superfície externa do tronco e interna ou externa à casca (Cooper, 1984; Cooper \& Grace, 1987 e Henderson et al., 1995), onde a presença de vestígios e/ou ataque de cupins pode indicar uma infestação interna.

No entanto, este tipo de diagnóstico torna-se limitado quando a infestação é causada pelos gêneros Coptotermes spp. e Reticulitermes spp, por exemplo, uma vez que $\mathrm{o}$ ataque pode acometer apenas o cerne e não aparecer no visual externo, tornando-se totalmente insuspeita a presença do cupim (Cooper \& Grace, 1987; Fontes, 1998 e Juttner, 1997).

Ocorrências de $C$. havilandi infestando o cerne, sem a presença de sinais exteriores, foram registradas por Fontes et al. (1997) em árvores, jovens e adultas, da cidade de São Paulo, que nunca haviam sofrido poda ou outras intervenções comuns 
no meio urbano. Devido a esta constatação, o autor afirma que esta espécie, conhecida como cupim-do-cerne, penetra pelas raízes das árvores, fato também observado por Juttner (1997) com C. formosanus, e constrói galerias pelo interior do tronco, destruindo o cerne e deixando as árvores ocas.

A partir das características deste tipo de infestação, este estudo também têm como objetivo realizar uma prospecção interna do tronco, por meio de uma análise não-destrutiva, para estimar a intensidade do ataque causado pelos cupins xilófagos. Até o momento, as referências bibliográficas que utilizam este tipo de análise detectam, entre outras ocorrências, o estado interno das árvores, mas sempre associados aos fungos apodrecedores e/ou deterioração, bem como a sua extensão, (Bethge et al., 1996; Dolwin, 1996; Dolwin et al., 1998; Habermehl 1982; Habermehl \& Ridder, 1995 e Reuter, 2000) e não mencionam nos cupins xilófagos.

Em New Orleans, pesquisadores utilizam o equipamento Sibtec DmP (Digital Micro Probe), pertencente ao grupo dos penetrômetros, no qual o Resistógrafo ${ }^{\circledR}$ também está inserido, para inspecionar o interior de árvores e verificar a presença de ocos e/ou galerias de cupins. Neste caso, com o intuito de tratar as árvores infestadas, pela injeção de produtos químicos nos espaços vazios, de acordo com Messenger (2001).

Além da infestação de cupins nas árvores, também chama a atenção o baixo índice de arborização constatado na cidade de São Paulo (Abbud, 1999).

É importante lembrar que as árvores podem desempenhar um papel vital para o bem estar das comunidades urbanas. A capacidade única das árvores em controlar muitos dos efeitos adversos do meio urbano, como por exemplo; a melhoria microclimática e a diminuição da poluição sonora, contribuindo para uma significativa melhoria da qualidade de vida, determina a necessidade de áreas verdes urbanas a serem manejadas como um recurso de múltiplo uso em prol de toda a comunidade (Johnston, 1985 citado por Milano, 1988).

\footnotetext{
${ }^{1}$ A menção da marca comercial, Resistógrafo ${ }^{\circledR}$, não tem qualquer intenção de propaganda.
} 
Portanto, torna-se necessário e de extremo interesse que as árvores existentes na cidade de São Paulo sejam preservadas. O estudo dessas infestações, com o aprimoramento do método de diagnóstico permitirá, por um lado, avaliar corretamente a suscetibilidade das árvores hoje plantadas no meio urbano, e por outro, fornecer informações que possibilitem selecionar quais são os indicadores externos que podem estar associados a ocorrência interna de cupins xilófagos nas árvores, além da verificação da intensidade da infestação. Estas informações poderão auxiliar na tomada de decisões visando a solução do problema.

\subsection{Objetivos}

\subsubsection{Geral}

Investigar as árvores urbanas do bairro de Higienópolis, quanto a ocorrência de cupins xilófagos, as suas condições gerais e de entorno.

\subsubsection{Específicos}

Verificar a existência de uma correlação entre os indicadores externos, previamente estabelecidos, com a ocorrência interna de cupins xilófagos em árvores urbanas, além de estimar a intensidade dessa infestação por meio de uma avaliação não-destrutiva.

\subsection{Justificativas}

As justificativas para a realização desta pesquisa são, principalmente, a escassez de informações relacionadas ao ataque de cupins xilófagos às árvores urbanas da cidade de São Paulo.

Este desconhecimento coloca em risco a população, uma vez que as árvores atacadas pelos cupins tornam-se mais sujeitas à queda, principalmente durante e após temporais e ventos fortes, prejudicando a integridade de pessoas, animais, veículos e edificações. Além disso, as árvores atacadas pelos cupins-subterrâneos podem ocasionar a infestação de edificações e prédios históricos e servirem de abrigo para estes insetos. 
A obtenção de informações relacionadas a esta problemática poderá auxiliar na tomada de decisões sobre a realização de tratamento curativo e/ou preventivo, o abate ou não de árvores infestadas, e no fornecimento de subsídios para análises quanto ao risco de queda das árvores. 


\section{REVISÃO DE LITERATURA}

\subsection{Ocorrências de cupins xilófagos}

Um dos primeiros casos documentando o ataque de cupins xilófagos em árvores urbanas foi observado por $\mathrm{H}$. A. Hagen em 1885. O autor verificou a presença de cupins da espécie Termes flavipes ${ }^{2}$ em uma árvore de Acer rubrum, localizada em um jardim, na cidade de Cambridge, nos Estados Unidos. De acordo com as observações do autor, a árvore apresentava-se com aspecto foliar exuberante e, de modo geral, em boas condições, exceto pelo fato da presença de algumas rachaduras na casca e, sob esta, a atividade de cupins.

No entanto, após um forte temporal, houve a ruptura da parte apical da árvore, não tendo sido observada, nessa região, a presença de cupins. Como medida de segurança a árvore foi removida por completo e foram feitas as seguintes constatações: a casca encontrava-se, nos locais de passagem dos cupins, intensamente perfurada; a madeira soterrada, localizada a $60 \mathrm{~cm}$ abaixo do solo, estava preenchida e atacada pelos cupins; e o cerne ao longo de $9 \mathrm{~m}$, encontrava-se intacto.

Cooper \& Grace (1987) também diagnosticaram o problema de cupins da espécie Reticulitermes flavipes em árvores no Canadá, e observaram que a infestação geralmente iniciava-se internamente na planta. Os cupins atacavam primeiramente as raízes seguindo para o cerne com poucas evidências aparentes da infestação. No entanto, quando estas evidências eram observadas, os túneis estavam presentes na superfície do tronco, interna e externa à casca; observaram que a presença dos túneis

\footnotetext{
${ }^{2}$ A espécie que o autor se refere é atualmente conhecida como Reticulitermes flavipes (Kollar). CONSTANTINO,R. Identificação de cupins. Constant@unb.br (10 Out. 2001).
} 
nem sempre precedia uma ferida, conforme verificaram também Esenther et al. (1961), citados por Cooper \& Grace (1987).

Tais feridas encontravam-se presentes em 54 \% das árvores infestadas, ainda que túneis também tivessem sido constatados nas árvores com feridas cicatrizadas, isto é, em 42 \% das árvores infestadas e, de maneira esporádica, em árvores que não apresentavam feridas aparentes.

O fato das árvores urbanas estarem sujeitas ao estresse e a danos físicos, não permitiu afirmar se a presença dos cupins, na superfície exterior e interior da casca, ocorreu em conseqüência destas áreas mortas ou feridas. Também não se tem conhecimento se a presença dos cupins nas áreas mortas e os túneis internos e externos à casca contribuíram para a mortalidade da árvore (Cooper \& Grace,1987).

De acordo com o trabalho desenvolvido por Cooper (1984), foram inspecionadas em Toronto, Canadá, 17.800 árvores de avenidas e parques, localizadas em áreas infestadas por cupins-subterrâneos da espécie Reticulitermes flavipes, com o intuito de identificar a espécie da árvore, seu diâmetro e as suas condições físicas.

Destas árvores, 700 tinham cupins e apenas 10 apresentavam ninhos, que se encontravam próximos ao solo, normalmente localizados nos cernes deteriorados. 0 autor concluiu que certas espécies de árvores eram mais atacadas do que outras e que, geralmente, os cupins eram mais freqüentes em árvores de grandes diâmetros, que apresentavam feridas deterioradas.

Nogueira \& Souza ${ }^{3}$, citados por Wilcken \& Raetano (1995), também observaram em florestas, que quanto maior o diâmetro de árvores de Eucalyptus sp., maior a freqüencia de árvores atacadas por Coptotermes testaceus.

Rhoads et al. (1979) concluíram que os cupins-subterrâneos da espécie Reticulitermes flavipes eram uma ameaça às árvores de rua da cidade de Filadélfia.

\footnotetext{
${ }^{3}$ NOGUEIRA, S.B.; SOUZA, A.J. "Cupim do cerne", Coptotermes testaceus (Isoptera: Rhinotermitidae), uma praga séria para eucaliptos nos cerrados. Brasil Florestal, v.61, p.27-29, 1987.
} 
Também informaram que a maioria das referências bibliográficas omitiam a ocorrência de cupins nas árvores e, quando a mencionavam, associavam a sua ocorrência somente à porção deteriorada das árvores.

No entanto, os autores detectaram a atividade de cupins em troncos sadios de árvores de "red oak" (Quercus rubra), "white basswood" (Tilia heterophylla), "thornless honey locust" (Gleditsia triacanthos var. inermis) e "ginkgo" (Ginkgo biloba), sendo que os locais de entrada dos cupins não pareciam estar relacionados com as feridas causadas por podas ou por rupturas existentes na casca.

Os autores também relataram que os prédios adjacentes à esta área haviam apresentado problemas de cupins, embora todos os escombros das construções tivessem sido cuidadosamente removidos das covas onde as árvores seriam definitivamente plantadas.

De acordo com Harris (1955), as podas mal executadas propiciam a entrada de uma variedade de cupins, uma vez que ferem e deixam tocos de galhos no tronco das árvores. Na África, Coptotermes spp. são freqüentemente encontrados nesta situação.

Segundo Becker (1975), as árvores ornamentais das ruas ou árvores frutíferas que se encontram plantadas em áreas infestadas por cupins, depois de podadas, podem tornar-se sujeitas ao ataque de fungos e cupins, que penetram através dos cortes, ocasionando um ataque intenso.

Kalshoven (1962) menciona que em florestas de teca na Indonésia, a infestação de Coptotermes havilandi (javanicus) havia sido a causa da morte de árvores. Segundo o autor, esta afirmação pode estar correta pelo fato das cavidades formadas no cerne se aproximarem dos tecidos vivos, que podem interferir com a circulação da seiva, particularmente, na copa, causando a seca de parte do topo das árvores. O gradual enfraquecimento e deterioração da árvore facultam à colônia de cupins o aumento na disponibilidade de alimento, o que irá fortalecê-la. Isto poderá ser um processo longo, visto que dependerá da dimensão original, do vigor da árvore e do tamanho da colônia. 
De acordo com Harris (1955), embora os cupins se alimentem dos tecidos da madeira morta, a atividade desses insetos é tal que propicia a morte progressiva dos tecidos vivos pela entrada de umidade e fungos nas feridas.

Segundo Becker (1975), vários gêneros de cupins atacam os tecidos mortos das árvores vivas. Os galhos deteriorados ou as partes internas do tronco são destruídas e, em alguns casos, a madeira sadia também pode ser atacada.

Corroborando a citação de Becker (1975), Oliveira (1986) menciona que a maioria das espécies xilófagas ataca os tecidos da madeira morta, porém algumas espécies podem atacar árvores vivas, Coptotermes havilandi, por exemplo. De acordo com Mathews (1977), algumas espécies do gênero Coptotermes spp., são aparentemente capazes de matar plantas vivas. Adamson (1943), já havia mencionado que este gênero foi observado danificando seringueiras na Malásia e outras árvores na Austrália.

Kalshoven (1963) concluiu em um estudo realizado nas florestas de Bandjar, na Indonésia, que nos locais com predominância de vegetação mista, algumas árvores eram mais atacadas ou mais susceptíveis aos cupins da espécie Coptotermes curvignathus.

Conforme citado anteriormente, Kalshoven (1962) constatou a infestação de Coptotermes havilandi (javanicus) em árvores que cresciam espontaneamente nas florestas de teca, na cidade de Gedangan, na Indonésia.

O autor observou que as colônias destes insetos estavam sempre associadas à morte e ao dano de árvores leguminosas (Albizzia lebbeckioides e Acacia tomentosa, entre outras). Isto permitiu ao autor afirmar que $C$. havilandi preferivelmente seleciona seus hospedeiros.

Por outro lado, de acordo com Hickin (1971), os cupins não são muito específicos com relação às espécies de árvores que eles atacarão, muito embora freqüentemente isto esteja condicionado à distribuição geográfica dos cupins e as espécies de árvores presentes.

Com relação à resistência das árvores ao ataque de cupins e fungos, como, por exemplo, a Mukulunga (Autranella congolensis), encontrada na República Centro- 
Africana, sabidamente resistente a estes organismos, Becker (1975), constatou que haviam sido infestadas no cerne por Coptotermes sjöstedti Holmgren. O interior de uma árvore dessa espécie apresentava-se deteriorado pelo ataque de fungos e, evidentemente, os cupins tinham atacado também as partes sadias do cerne.

É provável que o cerne tenha perdido parte de sua resistência natural devido ao fato da árvore ser antiga, possibilitando com isso que os fungos e cupins atacassem a madeira (Becker, 1975).

Mencionando a possibilidade da ligação existente entre uma árvore e uma edificação, Gay (1946) foi o primeiro pesquisador a documentar este fato. O autor observou o ataque causado por Coptotermes frenchi Hill a uma residência, onde parte das galerias subterrâneas da colônia foi ligada a um ninho localizado em uma árvore de eucalipto (Eucalyptus macrorrhyncha), morta, a uma distância de cerca de $20 \mathrm{~m}$ do imóvel.

A hipótese da associação da presença dos cupins com as edificações, é levantada por Cooper (1984) que documentou em seu estudo que, em parques, ravinas ou outras áreas abertas distantes das edificações, na prática, não haviam sido encontrados cupins.

Kofoid et al. (1934) observaram que a destruição da madeira causada por cupins é freqüentemente precedida pelo ataque dos fungos e que as condições favoráveis aos cupins, são também favoráveis aos fungos e, conseqüentemente, estes dois organismos são comumente encontrados juntos.

Kalshoven (1963) também considerou o ataque dos cupins como sendo secundário, onde ocorre, primeiramente, uma deterioração causada por fungos. Hickin (1971) relatou que os cupins são raramente considerados como pragas primárias e os danos causados às plantas, arbustos e árvores somente ocorrem quando estes já foram afetados pelo fogo, pelos fungos ou por insetos de outras ordens. No entanto, o fato dos cupins serem considerados como pragas secundárias, não quer dizer que eles sejam menos importantes. $O$ dano inicial à planta, causado pelo fogo, pelos fungos ou por outros insetos, é freqüentemente de menor importância, mas depois que permite o ingresso dos cupins o efeito pode ser a destruição completa da planta ou, no mínimo, uma redução nos valores de uma cultura. 
Por outro lado, em um estudo realizado por Greaves et al. $(1965,1967)$ citado por Perry et al. (1985), em floresta de eucalipto no sudeste da Austrália, foi observado que os danos dos cupins e dos fungos foram considerados independentes.

Com relação ao uso comercial da madeira, Greaves $(1960,1962)$ e Greaves et al. (1967), em Becker (1975), constataram prejuízos econômicos em larga escala quando houve a destruição do cerne por fungos e cupins das espécies Coptotermes acinaciformis (Frogatt), C. brunneus Gay e C. frenchi Hill em árvores de eucalipto, na Austrália. Becker (1975), menciona ainda, que este gênero é o principal grupo de cupins que infesta as árvores de florestas.

De acordo com Lai et al. (1983), que observaram o ataque de Coptotermes formosanus em plantas no Hawaii, existem muitas maneiras dos cupins danificarem uma planta. Primeiramente, no caso de árvores, o principal dano ocorre no cerne, fato também observado por Leonardo \& Barsotti (1998), com C. havilandi. Os cupins podem, ocasionalmente, construir túneis na superfície da árvore, indicando que a mesma encontra-se atacada, mesmo que externamente apresente aspecto saudável. Com relação a morte das plantas, os cupins podem se alimentar das raízes, o que freqüentemente ocorre com citrus e eucalipto; podem fazer o anelamento progressivo do tronco; e podem infestar, no caso de arbustos, todas as partes da planta ao mesmo tempo, podendo ser encontrados tanto no tronco, nas raízes, como nas partes comestíveis, como frutos, bulbos, etc.

Kalshoven (1963) menciona que o ataque de C. curvignathus em árvores monocotiledôneas, na maioria palmeiras, apresenta características especiais devido à anatomia da planta, ao sistema radicular e às reações muito diferentes daquelas das coníferas e dicotiledôneas.

No Hawaii, além destas ocorrências, $C$. formosanus também vem causando grandes perdas econômicas nas plantações de cana-de-açúcar. Na região sudeste do Brasil, danos a esta cultura também são causados por cupins das espécies Heterotermes tenuis, Procornitermes triacifer, Neocapritermes parvus e Cornitermes cumulans (Novaretti \& Fontes, 1998). 
Ainda no Hawaii, outras árvores ornamentais e frutíferas, tais como abacate, manga, hibisco, banana e muitas outras também são listadas dentre as 48 plantas atacadas por C. formosanus (Lai et al., 1983).

De acordo com Harris (1971), culturas como café, cacau, seringueira, chá e outras árvores e arbustos não são atacadas pelos cupins, mesmo nas regiões onde estes insetos estão presentes, caso estas plantas estejam crescendo sob ótimas condições. As plantas com maior susceptibilidade ao ataque de cupins, são aquelas que sofrem com a seca, com a presença de alguma ferida causada pelo descuido no uso da enxada, podas mal executadas ou danos causados por ventos fortes.

Becker (1975), constatou o ataque às árvores de teca (Tectona grandis) em plantações na Indonésia, sendo que a espécie encontrada era Neotermes tectonae (Damm.), pertencente à família Kalotermitidae Esta espécie uma vez estabelecida na árvore, destroi o cerne. A espécie Kalotermes approximatus Snyder pertencente à esta mesma família também foi observada por Hetrick (1953), atacando árvores de cerejeira preta (Prunus serotina Ehrh.), pereira (Pyrus communis L.), carvalho, "sweet gum" e magnólia.

De acordo com Hickin (1971), com exceção de um número de espécies de Coptotermes spp., os cupins não se alimentam de árvores vivas. Os tecidos mortos da madeira, mesmo se ainda ligada à árvore viva, são geralmente preferidos, especialmente pelos cupins mais primitivos da família Kalotermitidae, mas também por alguns gêneros mais evoluídos, tais como Amitermes, Microcerotermes e Nasutitermes.

Com relação aos hábitos alimentares, Adamson (1943) informa que não são conhecidos cupins que dependem de uma alimentação proporcionada por árvores vivas. Provavelmente em muitos, senão todos os casos, o ataque de cupins inicia-se nos tecidos mortos das árvores vivas, passando em seguida para a porção viva da árvore. 


\subsection{Avaliação não-destrutiva}

Este estudo, além de verificar as condições gerais da árvore a partir da inspeção visual externa e do local em que encontra-se plantada, possibilitará determinar com a utilização de um equipamento não-destrutivo, o Resistógrafo ${ }^{\circledR}$, a intensidade do ataque causado pelos cupins xilófagos nas árvores urbanas.

O Resistógrafo ${ }^{\circledR}$ foi fabricado na Alemanha, e introduzido nos Estados Unidos pela Instruments, Materials, Labor em 1995. Este equipamento foi um dos primeiros a ser desenvolvido utilizando o princípio da análise não-destrutiva (Dykema, 2001).

Por muito anos, uma das únicas ferramentas utilizadas, por exemplo, para detectar a presença de cavidades internas nas árvores ou o acesso as deteriorações, foi a sonda de Pressler, que removia amostras do cerne por meio de uma broca extratora (Catena et al., 1990 e Nicolotti \& Miglietta, 1998).

Contudo, como tratava-se de um método destrutivo, que ocasionava injúrias nas árvores, outros equipamentos conhecidos como não-destrutivos, foram desenvolvidos para, neste caso, analisar internamente as árvores. Estes aparelhos complementam a análise externa e permitem uma maior confiabilidade em condições de campo, uma vez que o acesso às árvores nãodeve ocorrer por apenas uma única avaliação, externa ou interna. Portanto, para se fazer um julgamento correto, será sempre necessário considerar a aparência geral da árvore (Dolwin, 1996 e Bethge et al., 1996).

De acordo com Barrett et al. (1987); Catena et al. (1990); Dolwin (1996); Dolwin et al. (1998); Habermehl et al. (1995); Mattheck \& Breloe (1997); Nicolotti \& Migliett (1998) e Seab (1990) outros métodos não-destrutivos podem ser utilizados para avaliar os defeitos também nas árvores. Entre estes, podem ser citados os condutores elétricos, detectores sônicos e ultrasônicos, termografia, radar e tomografia de raio $x$.

Ainda que não existam referências bibliográficas que mencionem a utilização da metodologia desenvolvida nesta pesquisa em relação a cupins xilófagos, foi realizado um estudo similar, que incluiu a análise externa e interna, em árvores de floresta na Malásia. O objetivo foi aumentar a eficiência da exploração florestal, evitando a colheita de árvores ocadas, que eram rejeitadas pelas empresas 
madeireiras. Além destas análises, Reuter (2000) acrescentou, parâmetros relacionados ao terreno, como uma forma de correlacioná-los com a deterioração interna do tronco. Estes parâmetros incluíram a presença e o tamanho das pedras e a distância de córregos.

Este estudo, bem como a presente pesquisa, remetem ao método VTA (Visual Tree Assessment) desenvolvido por Mattheck \& Breloer (1994), pelo menos com relação à duas etapas, que consistem na inspeção visual da árvore para encontrar sintomas externos de defeitos internos, e, em caso de necessidade, a utilização de um equipamento não-destrutivo, como por exemplo: "metriguard" e "fractometer", para avaliar a extensão do defeito interno que pode vir a tornar-se crítico. Contudo, o método VTA, baseado em princípios da biomecânica e no critério da tensão constante, tem como objetivo deduzir quais sintomas da árvore produzirão pontos vulneráveis como reação (Mattheck \& Breloer, 1997).

A escassez de informações relacionadas ao ataque de cupins xilófagos às árvores urbanas e a aparente dimensão deste problema em áreas de grande concentração populacional, como na cidade de São Paulo, indica claramente a necessidade da obtenção de informações mais completas e detalhadas referentes a esta problemática. 


\section{MATERIAL E MÉTODOS}

\section{1 Área de estudo}

Como área para investigação foi selecionado o bairro de Higienópolis, na cidade de São Paulo. Este bairro ocupa uma área de aproximadamente $725.000 \mathrm{~m}^{2}$, tendo como limites as Ruas Itambé, Pará, Rio de Janeiro e Avenida Higienópolis, como indicado no Código de Endereçamento Postal - CEP e conforme o mapa, no Anexo A.

Dentre as razões para a escolha deste bairro, estão o fato de que boa parte das árvores existentes nesta região encontra-se atacada por cupins, de acordo com Pantem (1999).

Este bairro apresenta-se também com ruas bem arborizadas (Sempla, 1988), tendo sido um dos primeiros, na cidade de São Paulo, a receber o plantio de árvores, uma vez que tiveram preferência os bairros residenciais de classe alta entre os anos de 1902 e 1903 (Goya, 1992).

Além destes fatores, estão presentes nesta região edificações históricas tombadas pelo Conselho de Defesa do Patrimônio, Histórico, Artístico, Arqueológico e Turístico do Estado de São Paulo - Condephaat, que são também referenciais de estilos arquitetônicos, como, por exemplo, o Colégio Nossa Senhora do Sion, a Vila Penteado, onde está instalada atualmente a Faculdade de Arquitetura e Urbanismo da USP, a Faculdade de Filosofia, Ciências e Letras da USP (Homem, 1980 e Instituto Cultural Itaú, 1996), além das residências de moradores ilustres da cidade de São Paulo. 


\subsection{Seleção das árvores}

Foi realizado o censo da população de árvores e arbustos do bairro de Higienópolis. Estes indivíduos encontram-se distribuídos de forma heterogênea em 27 quarteirões, conforme o mapa, no Anexo A. Esta contagem teve como objetivo conhecer o total da população arbórea, visando a seleção de indivíduos da amostra via amostragem aleatória. $\mathrm{O}$ sorteio foi feito tendo como base uma tabela de números aleatórios. Privilegiando o porte arbóreo dos indivíduos, fizeram parte deste sorteio apenas aquelas árvores que apresentaram um diâmetro a altura do peito (DAP) mínimo de $11 \mathrm{~cm}$. Para atender a um erro máximo admissível de $10 \%$ da média, foram sorteadas 49 árvores para a realização do estudo.

\subsection{Diagnóstico das árvores}

O estudo consistiu em diagnosticar as árvores quanto à sua sanidade biológica, ocorrência ou não de cupins xilófagos, por meio da análise da condição externa e da prospecção interna do tronco.

\subsubsection{Análise externa}

Esta análise foi executada por meio de:

a) verificação da presença de vestígios e túneis de cupins xilófagos na superfície do tronco, casca e entre casca, e no solo junto à base da árvore, além da avaliação da intensidade do ataque (Figura 4, Anexo B). Também foram inspecionadas, nos casos de suspeita da presença de oco e cupins, as forquilhas até uma altura aproximada de $1,80 \mathrm{~m}$ do solo.

b) análise visual das condições gerais da árvore, composta pelos seguintes atributos:

- aspecto saudável;

- presença de feridas (causadas por veículos, por exemplo) e/ou sinais de hostilidades no tronco e galhos;

- rachaduras na casca; 
- sinais de doença no tronco, como "galhas" (intumescência que ultrapassa o diâmetro do tronco);

- presença de oco;

- reentrâncias, que são ângulos ou curvas para dentro (Figura 4, Anexo B);

- intensidade da poda dos galhos.

c) análise visual das condições do entorno da árvore, ou seja, do local em que a mesma encontra-se plantada (Figura 5, Anexo B).

Estas análises com seus respectivos indicadores estão detalhadas na Planilha 1. Durante este diagnóstico e quando observados, foram coletados cupins, com uma pinça, e acondicionados em vidros com álcool a $75 \%$. Quanto a identificação das árvores, nos casos de dúvida, as folhas, frutos ou flores também foram coletadas.

Os cupins foram identificados pelo Departamento de Zoologia da Universidade de Brasília, DF, e as árvores, com o auxílio dos alunos do Instituto de Biociências da Universidade de São Paulo - USP.

\subsubsection{Prospecção e análise interna}

Esta prospecção teve como objetivos avaliar a intensidade do ataque de cupins xilófagos e verificar a sanidade biológica interna da árvore.

Para isto foram utilizados três equipamentos:

- o Resistógrafo ${ }^{\circledR}$, que registrou a possível perda de resistência mecânica da madeira causada pelo ataque de cupins;

- a furadeira para permitir a introdução da haste do boroscópio; e

- o "Boroscópio", que permitiu visualizar o dano no interior do tronco.

O Resistógrafo ${ }^{\circledR}$ é um equipamento que permite uma avaliação não-destrutiva das árvores (Figura 6, Anexo B). A empresa fornecedora deste produto é a Imlusa, IML - Instrument Mechanic Labor Inc., localizada em Marletta, GA, EUA. O modelo utilizado é o Resistógrafo F500, acoplado a uma furadeira marca Bosch.

O equipamento apresenta dois ajustes, um para madeira de maior densidade e outro para menor. Ao perfurar o tronco da árvore com uma velocidade constante, com uma broca de aço de $6 \mathrm{~mm}$ de diâmetro e $50 \mathrm{~cm}$ de comprimento, o Resistógrafo ${ }^{\circledR}$ 
permite indicar as diferenças de resistência mecânica da madeira do tronco, cujo resultado é registrado em um gráfico traçado pelo aparelho.

Neste estudo, o equipamento foi cedido pelo Prof. Dr. Mário Tomazello Filho do Laboratório de Anatomia e Identificação da Madeira da Escola Superior de Agricultura "Luiz de Queiroz" - ESALQ, USP.

O boroscópio é um sistema de endoscopia desenvolvido, também, para analisar os espaços vazios em edificações. A empresa fabricante do produto utilizado neste estudo é a KOM Lux Fibras Ópticas, localizada em Campinas, SP.

Este equipamento é composto de um cabo rígido de fibra ótica, com comprimento de $50 \mathrm{~cm}$ e diâmetro de $1,0 \mathrm{~cm}$, e de uma segunda haste giratória que, com um espelho em uma das extremidades, permite analisar o interior da árvore em $360^{\circ}$. Esta imagem é possível devido à ligação do cabo de fibra óptica a uma fonte geradora de luz. Este equipamento pertence ao Laboratório de Entomologia da Divisão de Produtos Florestais do IPT.

Ao detectar a perda de resistência da madeira do tronco com o Resistógrafo ${ }^{\circledR}$, executou-se a perfuração com uma furadeira Bosch modelo 1920.1, com uma broca de 2,0 cm de diâmetro, para permitir a introdução da haste do boroscópio, para visualizar o dano no interior da árvore, neste caso, de ocos e estruturas de ninho.

Nos casos em que a presença de oco interna era visível externamente, não foi necessária a realização da perfuração com a furadeira.

Durante a análise interna foram coletadas amostras de cupins, quando observados.

Para a realização destas análises em campo, foi utilizada uma bateria chumbo ácido da marca Panasonic de 12 watts com capacidade para 24 ampères/hora. 


\subsection{Determinação de classes de decaimento da resistência da madeira na prospecção interna}

Para a análise da possível perda da resistência mecânica da madeira causada pelo ataque de cupins xilófagos foi necessário, por meio da prospecção interna com o Resistógrafo ${ }^{\circledR}$, estabelecer uma classificação do decaimento da resistência da madeira, causada pelo ataque de cupins.

Esta classificação foi realizada após o término de todas as prospecções, onde os gráficos foram analisados e separados de acordo com os tipos de decaimento. Portanto, convencionou-se classificar o decaimento da seguinte forma:

1. nenhum decaimento;

2. decaimento leve a moderado, e

3. decaimento intenso.

Estas classes de decaimento estão indicadas na Planilha 1 (sub-item D), exemplificadas e discutidas no sub-item 4.3.1 e ilustradas no Anexo C.

\subsection{Trabalho de campo}

As 49 árvores sorteadas foram analisadas externamente de acordo com os indicadores estabelecidos no sub-item 3.3.1. Em seguida, foram prospectadas internamente com o Resistógrafo ${ }^{\circledR}$ realizando-se dois orifícios no tronco das árvores o mais próximo do solo, sendo que os mesmos cruzavam-se em um ângulo de 90․․

Após a análise de todas as leituras dos gráficos do Resistógrafo ${ }^{\circledR}$, foram estabelecidas as classes quanto à perda de resistência mecânica da madeira do tronco, conforme descrito no item 3.4. As árvores que apresentaram decaimento leve a moderado e intenso, foram perfuradas com uma furadeira no local da leitura que apresentou maior decaimento, exceto para aquelas que apresentavam ocos visíveis externamente. Neste orifício foi introduzida a haste do boroscópio para análise interna da árvore.

Após a análise interna, o orifício aberto pela broca da furadeira foi fechado com um batoque de madeira (Pinus sp.) tratado com o preservante de madeira CCB (solução de cobre, cromo e boro). 


\section{Planilha 1}

Indicadores externos ( $A, B$ e $C$ ) e internos ( $D$ e $E$ ), seus respectivos atributos e legendas para o diagnóstico das árvores.

A. Análise externa do tronco (An. Ext.)

0. sem sinais de cupins na casca e entre casca (S. Cup.)

1. com sinais de cupins, sem cupins vivos, na casca e/ou entre casca (C. S. Cup. Cas.)

2. com túneis, com cupins vivos, na casca e/ou entre casca (T. C. Cup. Cas.)

3a. ataque sem cupins aparentes (At. S. Cup.)

3b. ataque com cupins aparentes (At. C. Cup.)

4a. ataque intenso sem cupins aparentes (At. Int. S. Cup.)

4b. ataque intenso com cupins aparentes (At. Int. C. Cup.)

5a. ataque intenso, formando oco, sem cupins aparentes (At. Int. Oco S. Cup)

5b. ataque intenso, formando oco, com cupins aparentes (At. Int. Oco C. Cup.)

6. cupins vivos no solo junto a base (C. Cup. Bas.)

7. ataque com cupins vivos na reentrância (At. C. Cup. Reen.)

B. Condições gerais da árvore (Cond. Ger.)

1. sadia (Sad.)

2. feridas e/ou sinais de hostilidades (Fer.)

3. rachaduras na casca (Rach.)

4. sinais de doença (Doen.)

5. oco (Oco)

6. reentrâncias (Reen.)

7. poda leve (P. L.)

8. poda média (P. M.)

9. poda drástica (P. D.)

C. Condições de entorno (Cond. Ent.)

1. espaço adequado (Esp. Ad.)

2. espaço inadequado (Esp. In.)

3. espaço restrito ao tronco (Esp. Rest.)

4. duas árvores no mesmo espaço (Duas Árv.) 
D. Prospecção interna (resistência mecânica) (Prosp. Int.)

1. nenhum decaimento (N. Dec.)

2. decaimento leve a moderado (Dec. L. M.)

3. decaimento intenso (Dec. Int.)

E. Análise interna (boroscopia) (An. Int.)

1a. sem sinais de cupins (S. Cup.)

1b. com cupins vivos (C. Cup.)

2a. ataque, formando oco, sem cupins aparentes (At. Oco S. Cup.)

2b. ataque, formando oco, com cupins aparentes (At. Oco C. Cup.)

3a. ataque intenso, com estrutura de ninho, sem cupins aparentes (At. Int. Nin. S. Cup.)

3b. ataque intenso, com estrutura de ninho, com cupins aparentes (At. Int. Nin. C. Cup.)

\subsection{Correlação entre os atributos dos indicadores externos (A, B e C) com os atributos dos indicadores internos (D e E) das árvores}

A determinação dos atributos dos indicadores externos que poderiam estar associados com a ocorrência interna de cupins xilófagos nas árvores urbanas, foi feita por meio de análise de regressão múltipla, desenvolvendo-se dois modelos para as variáveis dependentes Prospecção Interna (Prosp. Int.) e Análise Interna (An. Int.).

Tendo em vista a forma como os dados para a análise foram codificados, conforme detalhado no sub-item 1.1 - Recodificação de dados, Anexo D, optou-se pela técnica de análise de regressão múltipla via componentes principais da matriz de correlação das variáveis independentes, conforme descrita por Jolliffe (1986) e explicada no sub-item 1.2 - Componentes Principais, no Anexo D.

Selecionados os componentes principais, passou-se para a etapa seguinte que foi a estimativa dos coeficientes dos modelos. Esse processo é descrito no subitem 1.3 - Análise de Regressão, no Anexo D.

Tendo em vista que todas as árvores analisadas em campo foram utilizadas para o desenvolvimento dos modelos, foi feita uma simulação de dados para testar a adequação dos mesmos. Para tanto, foram criadas 30 árvores da seguinte maneira: 
para cada um dos 14 atributos dos indicadores ( $\mathrm{A}, \mathrm{B}$ e $\mathrm{C}$ ), sorteou-se de uma tabela de números aleatórios, trinta números, zero ou um. O código zero correspondia à árvore que não apresentava o determinado atributo e o código um, no caso contrário. Quando os números sorteados para cada árvore criada não se apresentavam coerentes com o que havia sido observado na amostra das 49 árvores sorteadas em campo, estas situações foram devidamente corrigidas como, por exemplo, a presença de espaço inadequado e adequado.

Contudo, como os modelos completos apresentaram 14 atributos (variáveis independentes), foi feita a simplificação dos mesmos.

Essa simplificação foi realizada de maneira subjetiva: foram excluídas aquelas variáveis que apresentaram coeficientes com o valor zero na segunda casa decimal, que, conforme demostrado no Anexo D (Tabelas 8 e 9), não apresentam asterisco. 


\section{RESULTADOS E DISCUSSÃO}

\subsection{Censo das árvores no bairro de Higienópolis}

O censo apresentou uma população arbórea composta por 903 árvores e arbustos, sendo que apenas 617 árvores enquadraram-se no critério determinado para as análises, ou seja, diâmetro a altura do peito (DAP) de no mínimo $11 \mathrm{~cm}$.

Das 49 árvores sorteadas e analisadas, foram identificados os seguintes gêneros e espécies: alfeneiro (Ligustrum spp.), Oleaceae; tipuana (Tipuana tipu Benth.), Leguminosae; sibipiruna (Caesalpinia peltophoroides Benth.), Leguminosae; quaresmeira (Tibouchina granulosa Cogn.), Melastomataceae; ficus (Ficus spp.), Moraceae; pata-de-vaca (Bauhinia spp.), Leguminosae; espatódea (Spathodea campanulata Beauv.), Bignoniaceae e mamorana-da-terra-firme (Pseudobombax longiflorum), Bombacaceae.

As árvores mais freqüentes foram o alfeneiro, com $38 \%$ e a tipuana, com $16 \%$. A freqüencia relativa das demais árvores foi: $12 \%$ para a sibipiruna, $8 \%$, respectivamente, para espatódea e quaresmeira, $4 \%$ para ficus e pata-de-vaca e $2 \%$ para mamorana-da-terra-firme, conforme demonstrado no Gráfico 1. 


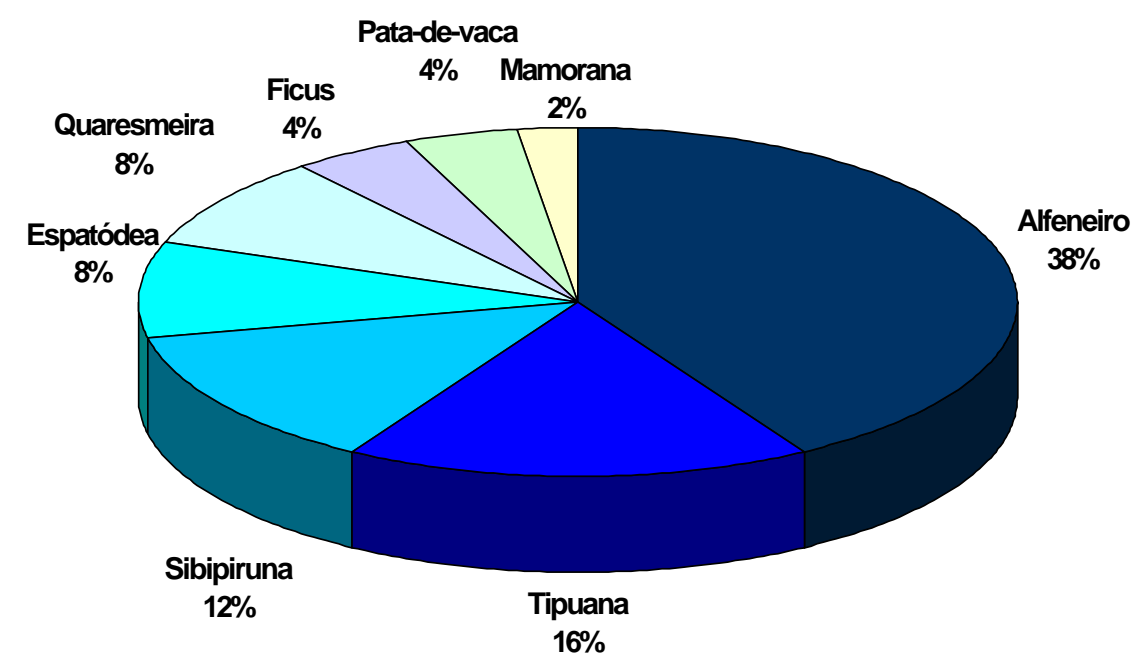

Gráfico 1 - Freqüencia das árvores pesquisadas

\subsection{Presença de cupins nas árvores}

De acordo com o levantamento de campo, registrado na Tabela 1, 35 das 49 árvores, ou seja, 71,4\%, apresentaram-se sadias, isto é, sem sinais externos ou internos da presença de cupins. As árvores com evidências, interna ou externa da presença de cupins, foram 14 que representaram 28,60 \%. Estes dados, bem como as informações sobre as árvores atacadas, estão detalhados no Gráfico 2: 


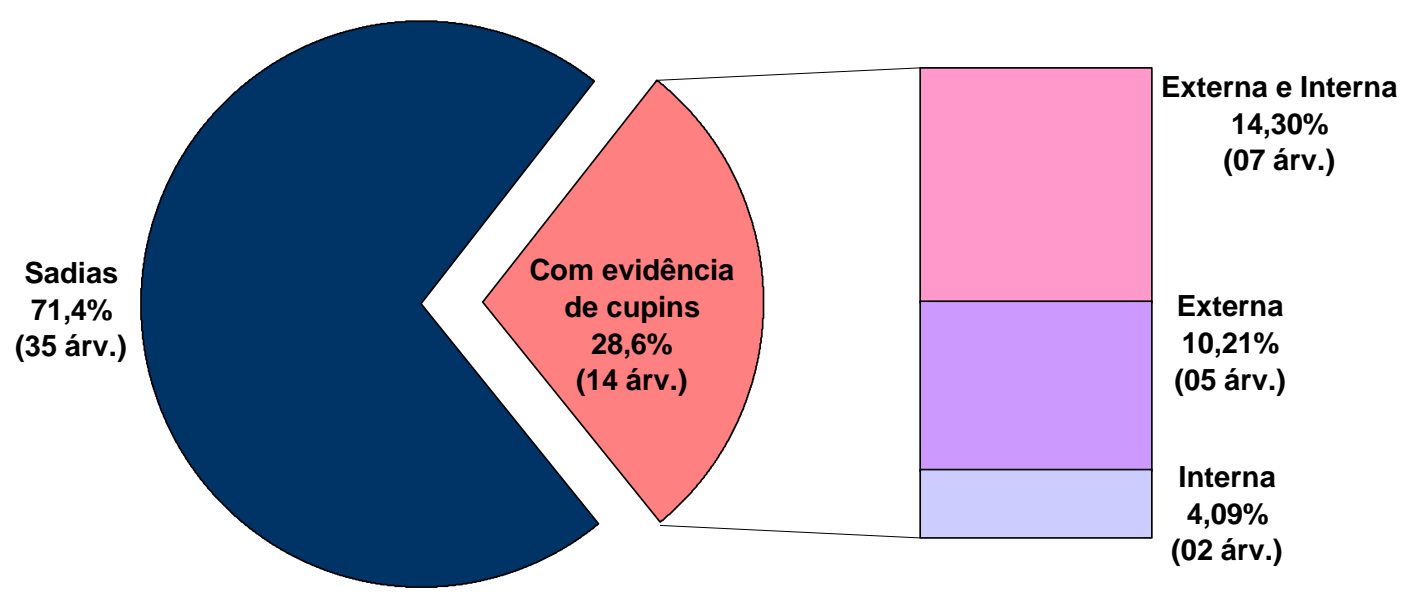

Gráfico 2 - Presença de cupins nas árvores

Analisando o Gráfico 2, nota-se a relativamente baixa presença de árvores com evidência de cupins (28,60 \%), no bairro de Higienópolis.

Destas, 14,30\% das árvores, ou seja, 07 indivíduos, apresentaram a ocorrência de cupins tanto externa como internamente. Neste caso, poderia ser levantada a hipótese de que quando a infestação em uma árvore é observada externamente, pela análise de pelo menos um dos seguintes atributos: ataque, ataque intenso ou ataque formando oco, pode-se inferir que haverá uma perda de resistência da madeira do tronco com a classificação de decaimento intenso. Portanto, a sanidade biológica interna estaria comprometida pela ação dos cupins. Em condições ideais, isto garantiria a existência de uma correlação entre a análise externa do tronco e a análise interna.

Entretanto, as árvores de número 08 e 24 registradas na tabela 1, apresentaram, na análise externa do tronco, túneis, com cupins vivos, na casca e/ou entre casca (T. C. Cup. Cas.) e ataque com cupins vivos na reentrância (At. C. Cup. Reen.), no caso da árvore 08 e ataque intenso, formando oco, com cupins aparentes (At. Int. Oco C. Cup.), na árvore 24. Estas árvores foram as únicas que tendo 
apresentado o decaimento da resistência da madeira, o apresentaram com intensidade leve a moderada.

A única exceção à hipótese levantada da existência de uma correlação do indicador externo com a ocorrência interna de cupins, foi representada pela árvore 49, que na prospecção interna, não apresentou decaimento de resistência da madeira, embora tendo sido observados cupins vivos no solo junto à base (C. Cup. Bas.) e ataque com cupins vivos na reentrância (At. C. Cup. Reen.). Esta situação pode ter ocorrido devido á realização da prospecção interna em um local de maior densidade da madeira (Eckstein \& Sass, 1994, citado por Reuter, 2000).

Foram registradas 05 árvores $(02,08,30,31$ e 49) que apresentaram a ocorrência de cupins apenas externamente, representando $10,21 \%$ do total de indivíduos. Destas, 02 árvores não apresentaram nenhum decaimento da resistência da madeira (árvores: 30 e 49). Neste caso, pode ser levantada a hipótese de que a infestação de cupins nestas árvores ainda não se apresenta intensa internamente.

As outras 03 árvores (02, 08 e 31), apresentaram decaimento leve a moderado. Neste caso, pode ter havido a ocorrência de madeira deteriorada pela ação de organismos xilófagos, cupins ou fungos. Alternativamente, a redução da resistência da madeira pode ter sido causada pela presença de madeira de menor resistência, com características de alburno, de acordo com Tomazello Filho ${ }^{4}$.

A presença de cupins apenas internamente em 02 árvores (28 e 43), ou seja, 4,09 \%, reforça as citações de Cooper \& Grace (1987); Fontes (1998) e Juttner (1997), de que a utilização apenas do diagnóstico externo pode não ser eficiente, visto que a infestação pode acometer apenas o cerne e não comprometer o visual externo. Neste dois casos, o decaimento da resistência da madeira mostrou-se intenso.

Em ambos os casos, poderia ser sugerido que a ocorrência de cupins tivesse se iniciado pelas raízes, conforme afirma Fontes et al. (1997) quando a constatação destes insetos não é diagnosticada externamente. Contudo, estas árvores apresentaram no diagnóstico das condições gerais, rachaduras na casca (Rach.),

\footnotetext{
${ }^{4}$ TOMAZELLO FILHO, M. (ESALQ, USP. Laboratório de Anatomia e Identificação da Madeira, Piracicaba). Comunicação pessoal, 2001.
} 
reentrâncias (Reen.) e poda média (P.M.), para a árvore 28 e feridas e/ou sinais de hostilidades (Fer.), oco (Oco) e poda média (P.M.), para a árvore 43.

Analisando alguns destes atributos, por exemplo, a poda, neste caso, com a intensidade média, pode permitir, em áreas infestadas por cupins, a ocorrência destes inseto e de fungos, que penetram através dos cortes, ocasionando um ataque intenso (Becker, 1975).

O atributo identificado como oco (Oco) que favorece a degradação dos tecidos pela presença de microorganismos (Barcelos, 2000), pode propiciar também uma condição favorável aos cupins, visto que estes insetos são considerados como pragas secundárias e as condições favoráveis ao fungos são também favoráveis aos cupins. Por essa razão, estes dois organismos são comumente encontrados juntos (Kalshoven, 1963 e Kofoid et al, 1934).

As árvores mais atacadas pelos cupins-subterrâneos foram o alfeneiro com $12 \%$ do total de árvores, a sibipiruna com $4 \%$ e o ficus, a espatódea e a tipuana com $2 \%$ cada.

Esta distribuição mostra que o alfeneiro apresentou maior número de ataque de cupins xilófagos, embora deva se levar em consideração que esta espécie também apresentou-se como a mais abundante.

Os cupins-subterrâneos coletados foram identificados como pertencentes à espécie Coptotermes havilandi Holmgren da família Rhinotermitidae, sendo que em apenas uma das 49 árvores foram observados resíduos de cupins da família Kalotermitidae, em oco, além do ataque de cupins-subterrâneos. 
Tabela 1. Registro do diagnóstico das árvores ${ }^{1}$

\begin{tabular}{|c|c|c|c|c|c|c|c|}
\hline Árvores & $\begin{array}{c}\text { Nomes } \\
\text { Vulgares }\end{array}$ & $\begin{array}{c}\text { DAP } \\
\mathrm{m}\end{array}$ & $\begin{array}{l}\text { An. } \\
\text { Ext. }\end{array}$ & $\begin{array}{l}\text { Cond. } \\
\text { Ger. }\end{array}$ & $\begin{array}{c}\text { Cond. } \\
\text { Ent. }\end{array}$ & $\begin{array}{l}\text { Prosp. } \\
\text { Int. }\end{array}$ & $\begin{array}{l}\text { An. } \\
\text { Int. }\end{array}$ \\
\hline 1 & Sibipiruna & 0,22 & 0 & 1,7 & 1 & 2 & $1 \mathrm{a}$ \\
\hline 2 & Sibipiruna & 0,30 & 6 & 1,2 & 3 & 2 & $1 \mathrm{a}$ \\
\hline 3 & Não identificada ${ }^{2}$ & 0,14 & 0 & $3,4,5,7$ & 1 & 1 & $1 \mathrm{a}$ \\
\hline 4 & Alfeneiro & 0,23 & 0 & $2,6,8$ & 3 & 1 & $1 \mathrm{a}$ \\
\hline 5 & Espatódea & 0,36 & 0 & 2,8 & 1 & 1 & $1 \mathrm{a}$ \\
\hline 6 & Quaresmeira & 0,11 & 0 & 4,7 & 1,4 & 1 & $1 \mathrm{a}$ \\
\hline 7 & Ficus & 0,33 & 0 & 4,8 & 1 & 1 & $1 \mathrm{a}$ \\
\hline 8 & Alfeneiro & 0,30 & 2,7 & $2,6,9$ & 2 & 2 & $1 \mathrm{a}$ \\
\hline 9 & Alfeneiro & 0,18 & 0 & $1,2,8$ & 1 & 1 & $1 \mathrm{a}$ \\
\hline 10 & Alfeneiro & 0,24 & 0 & $1,6,7$ & 3 & 1 & $1 \mathrm{a}$ \\
\hline 11 & Alfeneiro & 0,38 & 0 & 6,8 & 2 & 1 & $1 \mathrm{a}$ \\
\hline 12 & Ficus $^{3}$ & 0,70 & $4 b$ & $2,4,5,8$ & 3 & 3 & $2 a$ \\
\hline 13 & Quaresmeira & 0,13 & 0 & $2,4,6$ & 3 & 2 & $1 \mathrm{a}$ \\
\hline 14 & Alfeneiro & 0,43 & 0 & 4,8 & 3 & 3 & $1 \mathrm{a}$ \\
\hline 15 & Pata-de-vaca & 0,17 & 0 & $1,3,7$ & 1 & 1 & $1 a$ \\
\hline 16 & Alfeneiro & 0,37 & 0 & 2,7 & 1 & 1 & $1 \mathrm{a}$ \\
\hline 17 & Alfeneiro & 0,41 & 0 & 5,8 & 1 & 1 & $1 \mathrm{a}$ \\
\hline 18 & Alfeneiro & 0,46 & $2,5 b, 7$ & 6,8 & 3 & 3 & $1 b$ \\
\hline 19 & Sibipiruna & 0,11 & 0 & $1,2,7$ & 3 & 1 & $1 \mathrm{a}$ \\
\hline 20 & Quaresmeira & 0,13 & 0 & $2,3,7$ & 1 & 1 & $1 \mathrm{a}$ \\
\hline 21 & Quaresmeira & 0,17 & 0 & $2,4,8$ & 1 & 1 & $1 \mathrm{a}$ \\
\hline 22 & Alfeneiro & 0,17 & 0 & $1,6,7$ & 2,4 & 1 & $1 \mathrm{a}$ \\
\hline 23 & Sibipiruna & 0,23 & $2,4 b$ & $1,2,5,6,8$ & 3 & 3 & $1 b$ \\
\hline 24 & Alfeneiro & 0,41 & $5 b$ & $1,2,5,6,8$ & 3 & 2 & $3 b$ \\
\hline 25 & Mamorana & 0,21 & 0 & 1,2 & 1 & 1 & $1 \mathrm{a}$ \\
\hline 26 & Alfeneiro & 0,40 & $1,5 a$ & $2,5,8$ & 3 & 3 & $3 a$ \\
\hline 27 & Alfeneiro & 0,14 & 0 & 5,8 & 3 & 1 & $1 a$ \\
\hline 28 & Espatódea & 0,29 & 0 & $3,6,8$ & 3 & 3 & $1 b$ \\
\hline 29 & Espatódea & 0,24 & 0 & 6,8 & 3 & 2 & $1 \mathrm{a}$ \\
\hline 30 & Alfeneiro & 0,21 & 1,6 & 8 & 2 & 1 & $1 a$ \\
\hline
\end{tabular}


Tabela 1. Registro do diagnóstico das árvores ${ }^{1}$

\begin{tabular}{|c|c|c|c|c|c|c|c|}
\hline Árvores & $\begin{array}{c}\text { Nomes } \\
\text { Vulgares }\end{array}$ & $\begin{array}{c}\text { DAP } \\
m\end{array}$ & $\begin{array}{l}\text { An. } \\
\text { Ext. }\end{array}$ & $\begin{array}{l}\text { Cond. } \\
\text { Ger. }\end{array}$ & $\begin{array}{c}\text { Cond. } \\
\text { Ent. }\end{array}$ & $\begin{array}{l}\text { Prosp. } \\
\text { Int. }\end{array}$ & $\begin{array}{l}\text { An. } \\
\text { Int. }\end{array}$ \\
\hline 31 & Não identificada ${ }^{2}$ & 0,25 & 2 & $2,3,4,8$ & 3 & 2 & $1 a$ \\
\hline 32 & Alfeneiro & 0,26 & $5 b$ & 4,8 & 3 & 3 & $2 a$ \\
\hline 33 & Tipuana & 0,44 & $5 a^{4}$ & 5,8 & 2 & 3 & $2 a$ \\
\hline 34 & Sibipiruna & 0,18 & 0 & 2,7 & 1 & 1 & $1 \mathrm{a}$ \\
\hline 35 & Tipuana & 0,68 & 0 & $1,6,8$ & 3 & 3 & $1 \mathrm{a}$ \\
\hline 36 & Tipuana & 0,41 & 0 & $1,2,6,9$ & 1 & 2 & $1 \mathrm{a}$ \\
\hline 37 & Tipuana & 0,43 & 0 & $1,2,6,9$ & 1 & 1 & $1 \mathrm{a}$ \\
\hline 38 & Alfeneiro & 0,18 & 0 & $2,4,8$ & 1 & 1 & $1 \mathrm{a}$ \\
\hline 39 & Alfeneiro & 0,35 & 0 & $2,6,8$ & 3 & 1 & $1 \mathrm{a}$ \\
\hline 40 & Alfeneiro & 0,26 & 0 & 8 & 3 & 1 & $1 \mathrm{a}$ \\
\hline 41 & Alfeneiro & 0,27 & 0 & $2,6,8$ & 1 & 1 & $1 \mathrm{a}$ \\
\hline 42 & Sibipiruna & 0,26 & 0 & 8 & 1 & 1 & $1 \mathrm{a}$ \\
\hline 43 & Tipuana & 0,55 & 0 & $2,5,6,8$ & 3 & 3 & $2 a$ \\
\hline 44 & Tipuana & 0,53 & 0 & 5,8 & 3 & 1 & $1 \mathrm{a}$ \\
\hline 45 & Ficus & 0,18 & 0 & $1,2,6,7$ & 1 & 1 & $1 \mathrm{a}$ \\
\hline 46 & Pata-de-vaca & 0,15 & 0 & $2,3,6,7$ & 1 & 1 & $1 \mathrm{a}$ \\
\hline 47 & Tipuana & 0,56 & 0 & 6,8 & 1 & 3 & $1 \mathrm{a}$ \\
\hline 48 & Espatódea & 0,45 & 0 & 2,8 & 2 & 2 & $1 \mathrm{a}$ \\
\hline 49 & Tipuana & 0,70 & 6,7 & 6,8 & 2 & 1 & $1 \mathrm{a}$ \\
\hline
\end{tabular}

${ }^{1}$ Esta tabela, usada para coleta de dados, foi baseada na proposta desenvolvida por Takahashi e Dalcin (1994).

2 As árvores de números 03 e 31 não puderam ser identificadas, devido à ausência de caracteres importantes, como por exemplo; folhas, flores e frutos, no momento das análises. Além disso, a árvore 03 havia caído, não sendo possível avaliar o motivo da queda.

${ }^{3} \mathrm{~A}$ árvore de número 12 apresentou estrutura de ninho inativa em galho quebrado.

${ }^{4}$ A árvore de número 33 foi a única que apresentou, durante a análise externa do tronco, resíduos de cupins da família Kalotermitidae em oco.

Os atributos dos indicadores An. Ext., Cond. Ger., Cond. Ent., Prosp. Int. e An. Int., são aqueles descritos na Planilha 1. 


\subsection{Prospecção interna com o Resistógrafo ${ }^{\circledR}$}

Durante a realização da prospecção interna nas árvores, foi necessário restringir, para alguns casos, a prospecção até a metade do diâmetro das árvores. Isto se deu em decorrência da dificuldade do Resistógrafo ${ }^{\circledR}$ perfurar madeiras densas e destas madeiras impedirem o avanço da broca (Gruber, 2000). A adoção desse critério teve como finalidade completar a totalidade das prospecções nas 49 árvores sorteadas, sem forçar demasiadamente o equipamento.

Esta prática não comprometeu a execução da prospecção interna, visto que a segunda metade do registro demonstrou não ser confiável, pois esta determinação não seria a mesma caso a prospecção fosse iniciada pelo lado oposto.

Isto pode ser explicado por alguns fatores como por exemplo, a ocorrência de atrito da haste da broca com a parede interna do tronco, à medida em que a broca penetra a uma certa profundidade, ocasionando um aumento da resistência em relação ao valor original detectado na ponta da broca, de acordo com Nicolotti \& Miglietta, 1998 e Tomazello Filho ${ }^{4}$.

O Resistógrafo ${ }^{\circledR}$ apresentou sérios problemas mecânicos, que podem estar relacionados à densidade da madeira das árvores analisadas, à utilização intensa e contínua do equipamento em um mesmo período e por fim, às várias tentativas de conserto realizadas por técnicos não especializados.

\subsubsection{Intensidades de decaimento}

Os registros exemplificados a seguir, representam o decaimento da resistência mecânica da madeira, em três classes de intensidade, conforme descrito no subitem 3.4.

A Figura 1 mostra o registro da leitura classificada como de nenhum decaimento. 


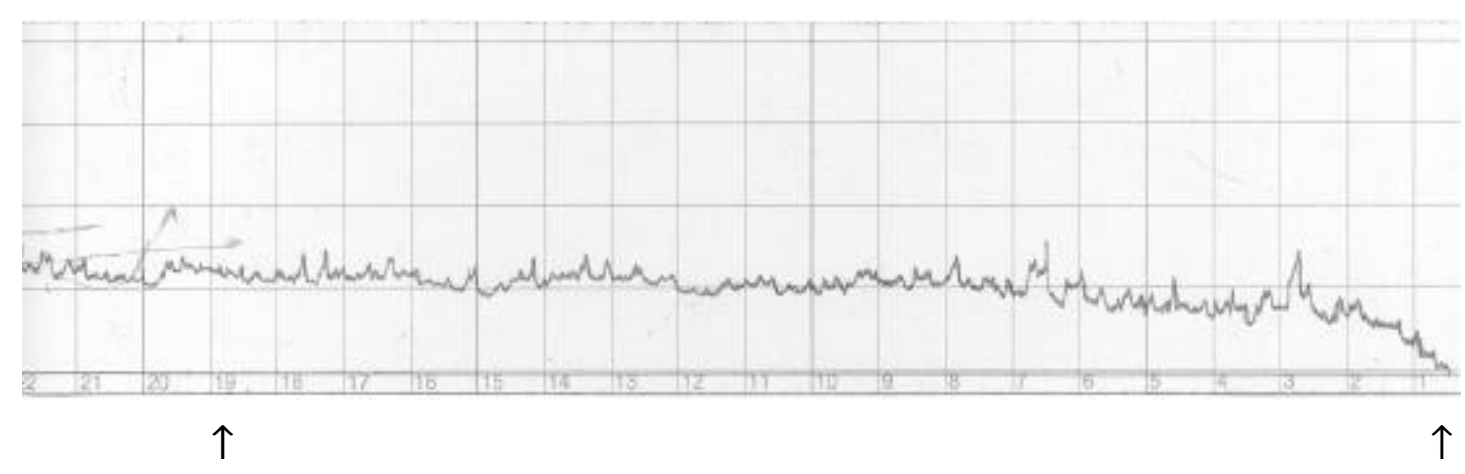

Centro

Casca

Distâncias em cm

Figura 1 - Gráfico da prospecção interna da árvore alfeneiro, registrada com o número 11, na Tabela 1.

O ponto identificado pela seta à direita, indica o momento da entrada da broca na casca da árvore e à esquerda, a região central do caule.

De maneira geral, a leitura do gráfico mostra-se contínua, sem maiores variações. Com isso supõe-se que esta árvore apresenta-se interiormente sadia.

Com relação à altura da leitura registrada no gráfico, esta pode estar relacionada às características anatômicas da árvore analisada e não da espécie.

Conforme a Tabela 1, pode ser observado que em todas as prospecções internas classificadas como; nenhum decaimento (N. Dec.), não foi observada a ocorrência interna de cupins-subterrâneos.

Com relação às condições gerais da árvore, foi constatada a presença de reentrâncias e poda média, sendo que o local onde a árvore encontrava-se plantada foi considerado inadequado.

A Figura 2 ilustra a ocorrência de decaimento leve a moderado. 


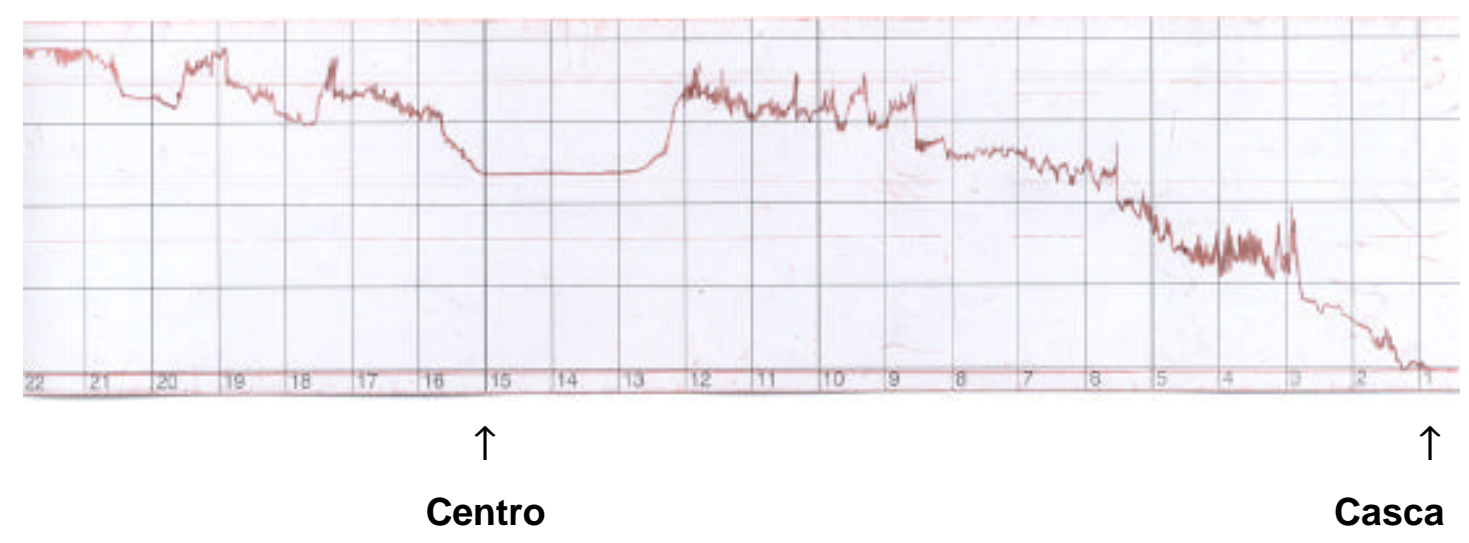

Distâncias em cm

Figura 2 - Gráfico da prospecção interna da árvore sibipiruna, registrada com o número 02, na Tabela 1.

O segmento entre 3 e $7 \mathrm{~cm}$, registra um aumento da resistência da madeira, enquanto que o de 9 a $12 \mathrm{~cm}$, demonstra picos e depressões que podem indicar a localização de zonas de diferentes densidades da madeira. Observa-se um decaimento que se estende de 12 a $15 \mathrm{~cm}$, aproximadamente, retornando a um registro normal a partir de $16 \mathrm{~cm}$.

De acordo com Dolwin et al. (1998), a resistência à penetração pode variar entre espécies e também entre diferentes árvores da mesma espécie. Também pode variar entre diferentes partes das árvores, dependendo de fatores como o padrão de crescimento, a presença de extrativos, resinas e de madeira de reação e também a variação de densidade (Eckstein \& Sass, 1994 em Reuter, 2000) .

Segundo os mesmos autores, alguns fatores podem explicar o decaimento da leitura da Figura 2, como por exemplo, a broca ser um pouco flexível e nem sempre seguir uma linha reta dentro da madeira, podendo desviar-se do seu caminho radial. Além disto, pode haver a presença de zonas deterioradas pela ação de fungos.

Ressalta-se que a redução da densidade no perfil nem sempre está relacionada a alguma zona de deterioração (Reuter, 2000). 
O decaimento pode ocorrer pela presença de madeira de menor resistência, com características de alburno. Além disso, a presença da medula, porção de menor resistência, no local do decaimento, também pode ter causado esta leitura, de acordo com Tomazello Filho ${ }^{4}$.

O distanciamento da broca em relação à casca, os prováveis movimentos operatórios acrescidos do friccionamento da broca contra as paredes no interior do tronco, também podem ocasionar uma redução na qualidade do perfil (Chantre \& Rozenberg, 1997 e Nicolotti \& Miglietta, 1998).

$\mathrm{Na}$ Tabela 1, pode ser observado que em todas as prospecções internas classificadas como de decaimento leve a moderado (Dec. L. M.), não foi observada a ocorrência interna de cupins-subterrâneos, exceção feita à árvore24.

Com relação às condições gerais da árvore 02, esta apresentou aspecto saudável e poda leve; enquanto o local em que encontrava-se plantada foi considerado adequado.

A Figura 3, indica a ocorrência de decaimento intenso.

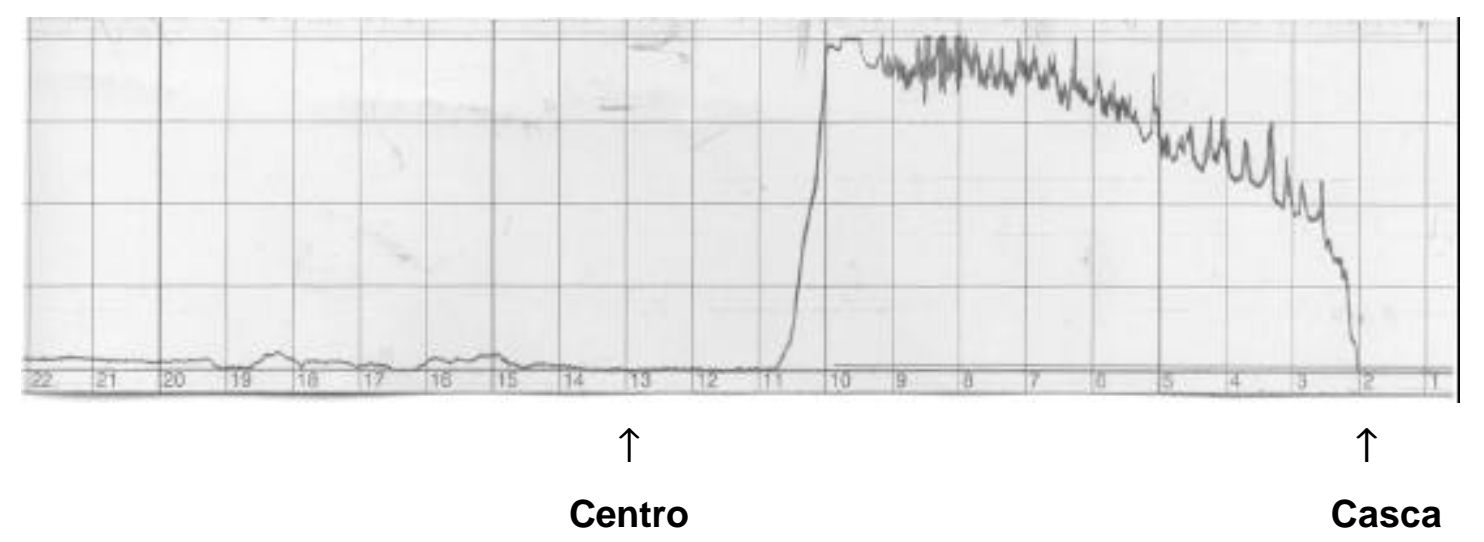

Distâncias em cm

Figura 3 - Gráfico da prospecção interna da árvore alfeneiro, registrada com o número 32, na Tabela 1. 
Como pode ser observado na Figura 3, o decaimento é notável a partir da marca dos $10 \mathrm{~cm}$.

Na Tabela 1, observa-se que o decaimento intenso apresentou relação com a ocorrência de cupins-subterrâneos em 7 das 14 árvores com cupins, sendo que em apenas 3 situações de decaimento intenso, não foi diagnosticada a presença deles.

É importante salientar que a constatação dos cupins pode ter sido precedida pelo ataque de fungos, uma vez que as condições favoráveis aos cupins, são também favoráveis aos fungos e, conseqüentemente, estes dois organismos são comumente encontrados juntos, conforme mencionado por Kalshoven (1963) e Kofoid et al. (1934).

$\mathrm{Na}$ análise da árvore 32, foi detectado externamente ataque intenso de cupins-subterrâneos, com insetos vivos e a presença de oco. Internamente, a mesma ocorrência de ataque, formando oco, foi observada em menor intensidade e sem a presença de insetos vivos.

Com relação às condições gerais da árvore, foram constatados sinais de doença e poda média, e nas condições de entorno, o espaço encontrava-se mais ou menos restrito ao tronco.

É importante ressaltar que o Resistógrafo ${ }^{\circledR}$ registra apenas os dados que encontram-se na área de passagem da broca, portanto não oferece indícios da extensão do problema verticalmente.

Outros exemplos das três classes de decaimento, estão ilustrados no Anexo C.

\subsection{Análise interna com o Boroscópio}

O exame do dano no interior das árvores com o boroscópio, em alguns casos, não foi adequado. Isto foi causado pelo curto comprimento da haste e o tamanho da área a ser examinada, no sentido axial, podendo tornar a imagem distorcida. 
4.5 Correlação entre os atributos dos indicadores externos e a ocorrência interna de cupins

\subsubsection{Modelos completos para Prospecção Interna e Análise Interna}

Partindo do modelo linear aditivo para os oito componentes principais, descrito pela equação a seguir:

$$
\mathbf{Y}=\mathbf{A}+\gamma_{1} \mathbf{X}_{1}+\gamma_{2} \mathbf{X}_{2}+\gamma_{3} \mathbf{X}_{3}+\gamma_{4} \mathbf{X}_{4}+\gamma_{5} \mathbf{X}_{5}+\gamma_{6} \mathbf{X}_{6}+\gamma_{7} \mathbf{X}_{7}+\gamma_{8} \mathbf{X}_{8}+\delta
$$

onde:

Y - vetor de n observações da variável dependente;

A - constante do modelo;

$\gamma$ - coeficientes dos oito componentes principais;

$\mathbf{X}$ - componentes principais;

$\boldsymbol{\delta}$ - vetor dos erros,

e aplicando-se a expressão (5), conforme sub-item 1.3 - Análise de Regressão, no Anexo D, os seguintes modelos, com os respectivos valores dos coeficientes de determinação e da probabilidade de significância, foram desenvolvidos para estimar a Prospecção Interna (Prosp. Int.) e a Análise Interna (An. Int.) em função dos atributos:

Prosp. Int. $=0,282629+0,229134$ * An. Ext. $+0,03647 *$ Sad. $+0,055729 *$ Fer. + $0,094591{ }^{*}$ Rach. $-0,19311{ }^{*}$ P. L. $+0,551111{ }^{*}$ P. D. $-0,03754{ }^{*}$ P. M. + 0,106882 * Doen. $+0,047479 *$ Oco $+0,090172$ * Reen. $-0,18917$ * Esp. Ad. $-0,0411{ }^{*}$ Esp. In. $+0,218237^{*}$ Esp. Rest. $-0,06249$ * Duas Árv..

$$
R^{2}=0,42 ; p=0,00279
$$

An. Int. $=0,016416+0,374881 *$ An. Ext. $+0,011016 *$ Sad. $+0,009907 *$ Fer. + $0,064563{ }^{*}$ Rach. $-0,02967 *$ P. L. $-0,09902^{*}$ P. D. $+0,078507 *$ P. M. 0,08575 * Doen. $+0,275786$ * Oco $-0,0246 *$ Reen. $-0,05762$ * Esp. Ad. $0,08582{ }^{*}$ Esp. In. $+0,118306{ }^{*}$ Esp. Rest. $-0,05953{ }^{*}$ Duas Árv..

$$
\mathrm{R} 2=0,44 ; p=0,00152
$$

O processo utilizado para estimar os coeficientes dos modelos, é apresentado no sub-item 1.3 - Análise de Regressão, no Anexo D. 
Como pode ser observado pelos valores das probabilidades de significância, os modelos são significantes tanto ao nível de $5 \%$ como de $1 \%$ de significância, o que vem a demonstrar a sua viabilidade.

\subsubsection{Processo de simulação}

A aplicação dos modelos completos para estimar a Prospecção Interna e a Análise Interna nas árvores simuladas, resultou em um acerto de 56,7\% e 50\%, respectivamente. Estas porcentagens podem ser consideradas como razoáveis tendo em vista o processo de recodificação que foi aplicado nos dados originais e utilizado nas árvores simuladas.

\subsubsection{Modelo simplificado para a Prospecção Interna}

Prosp. Int. $=0,282629+0,229134{ }^{*}$ An. Ext. $-0,19311 *$ P. L. $+0,551111 *$ P. D. + $0,106882{ }^{*}$ Doen. $-0,18917{ }^{*}$ Esp. Ad. $+0,218237{ }^{*}$ Esp. Rest.

Fizeram parte deste modelo simplificado, os seguintes atributos: análise externa, podas leve e drástica, sinais de doença e os espaços adequado e restrito ao tronco.

Este modelo, aplicado aos dados simulados, obteve um acerto de $60 \%$, ou seja da possibilidade de ser, ou não, observado o decaimento, o que pode ser considerado como razoável.

Os atributos selecionados subjetivamente para compor este modelo: An. Ex., P.L., P.D., Esp. Ad. e Esp. Rest., embora do ponto de vista prático, demonstram incoerência com os resultados que se esperavam. Deve-se levar em consideração que os coeficientes a eles associados são o resultado de um processo de cálculo matemático.

Esse resultado foi obtido de uma amostra de 49 árvores sorteadas aleatoriamente da população considerada. Uma outra amostra sorteada poderia resultar em uma resposta diferente da análise estatística e também da seleção dos atributos para compor o modelo simplificado. 
É importante observar que associação entre variáveis não implica em causaefeito tanto que o modelo simplificado obteve um índice de acerto superior ao modelo completo.

\subsubsection{Modelo simplificado para a Análise Interna}

An. Int. $=0,016416+0,374881{ }^{*}$ An. Ext. $+0,275786{ }^{*}$ Oco $+0,118306{ }^{*}$ Esp. Rest.

Fizeram parte deste modelo simplificado, os seguintes atributos: análise externa, presença de oco e o espaço restrito ao tronco.

Este modelo, caracterizado pelos três atributos mencionados acima, obteve um acerto em torno de 50 \% para a ocorrência, ou não, de cupins internamente.

A seleção subjetiva destes atributos, do ponto de vista prático, demonstrou coerência com os resultados que se esperavam, uma vez que para os casos da seleção dos atributos, análise externa e presença de oco, possibilitou determinar a ocorrência de cupins internamente em 50 \% dos casos, conforme demonstrado no subitem 4.2.

Como se observa, o índice de acerto deste modelo é semelhante ao índice obtido com o modelo completo, indicando assim que mesmo com o critério subjetivo de simplificação, o modelo continuou apropriado.

\subsection{Outras análises}

De acordo com as condições gerais das árvores, foi observado que $53 \%$ apresentaram feridas e/ou sinais de hostilidades; $43 \%$ apresentaram reentrâncias; $28 \%$ foram consideradas saudáveis e $20 \%$ apresentaram sinais de doença no tronco. A doença diagnosticada é denominada "galha", na qual se forma uma intumescência que ultrapassa o diâmetro do tronco.

Quanto às outras análises, foi observado que $18 \%$ das árvores apresentaram ocos e $12 \%$, rachaduras. 
Também foi observado que $94 \%$ das árvores apresentaram sinais de poda, das quais $24 \%$ poda leve, $63 \%$ poda média e $6 \%$ poda drástica. Verificou-se também que a presença de podas ocorre mesmo na ausência da fiação elétrica aérea.

Foi observada também a baixa diversidade de espécies arbóreas, calculada de acordo com o índice de diversidade de Shannon-Weaver (Ricklefs, 1993). Este índice foi calculado pela equação:

$$
\mathbf{H}=-\Sigma p i \log _{\mathrm{e}} \boldsymbol{p i} \text {, na qual: }
$$

onde:

$\mathrm{H}=$ índice de Shannon-Weaver;

$p i=$ proporção das espécies na amostra total de indivíduos.

O índice calculado foi igual a 0,76, sendo que a diversidade é considerada alta para arborização urbana quando este índice é superior a 3, de acordo com Couto ${ }^{5}$.

Em relação à distribuição das árvores, de modo geral os quarteirões apresentam em média uma árvore a cada $23 \mathrm{~m}$ de calçada, o que significa que existem 43 árvores por km. Esta distribuição é inferior àquela recomendada, que é de uma árvore a cada 7 a 12 m (Mello Filho, 1985).

5 COUTO, H.T.Z. (ESALQ, USP. Laboratório de Métodos Quantitativos, Piracicaba). Comunicação pessoal, 2001. 


\section{CONCLUSÕES}

O diagnóstico das árvores possibilitou com a utilização de apenas os atributos da análise externa do tronco: ataque (At.), ataque intenso (At. Int.) e ataque intenso formando oco (At. Int. Oco), determinar a existência de uma correlação destes com a presença interna de cupins-subterrâneos.

Além disso, o modelo estatístico simplificado, caracterizado pelos atributos: análise externa (An. Ext.), presença de oco (Oco) e espaço restrito ao tronco (Esp. Rest.), acertou em torno de 50 \% a ocorrência, ou não, de cupins internamente.

Devido à pequena amostra selecionada, este estudo apenas possibilitou indicar que algumas espécies apresentaram maior susceptibilidade ao ataque de cupins-subterrâneos. Neste caso, o alfeneiro pertencente ao gênero Ligustrum spp., da família Oleaceae, apresentou o maior número de árvores atacadas.

Para o caso da estimativa do ataque causado pelos cupins-subterrâneos nas árvores, o Resistógrafo ${ }^{\circledR}$ apresentou-se mais adequado para avaliar a classe de decaimento intenso do que as outras classes. Assim, decaimentos de menor intensidade podem ser difíceis de serem detectados ou diferenciados de variações da densidade da madeira ou de outras características presentes nas árvores. 


\subsection{Conclusões adicionais e recomedações}

Em adição às conclusões acima apresentadas, tornase evidente ainda a necessidade de se estudar melhor a correlação entre os demais atributos dos indicadores pertencentes às condições gerais e de entorno das árvores, e a ocorrência interna de cupins.

Também é desejável que estudos futuros verifiquem, além da possível correlação de outros indicadores externos com a ocorrência interna de cupins, a susceptibilidade das diversas espécies de árvores ao ataque de cupins xilófagos.

É interessante que em outras pesquisas, algumas árvores urbanas possam ser abatidas após a realização da prospecção interna, para verificação dos danos interiores e fornecer subsídios para melhorar a interpretação dos gráficos, principalmente, nos casos de decaimentos de menor intensidade.

Ficou evidente também, que as árvores urbanas estão sujeitas à condições adversas como, por exemplo, os efeitos diretos ou indiretos da concentração populacional, a compactação do solo, a poluição do ar e do solo e o ataque de pragas, fungos e doenças, o que torna necessária a seleção de espécies mais resistentes.

Também foi observada a baixa diversidade de espécies arbóreas, o que demonstra a necessidade de um replanejamento na seleção de novas espécies a serem introduzidas no bairro.

Empresas que produzem equipamentos na linha dos métodos não-destrutivos deveriam desenvolver aparelhos que não fossem invasivos e que permitissem a detecção do agente causador do dano.

É importante salientar que a avaliação das árvores necessita ser também realizada na área de raízes, uma vez que, alguns autores apontam que freqüentemente a queda de árvores nas cidades, é causada pelo apodrecimento das raízes. Este fato confirma a necessidade de estudos mais aprofundados da relação entre fungos apodrecedores e cupins xilófagos. 
ANEXOS 
ANEXO A

Mapa do bairro de Higienópolis

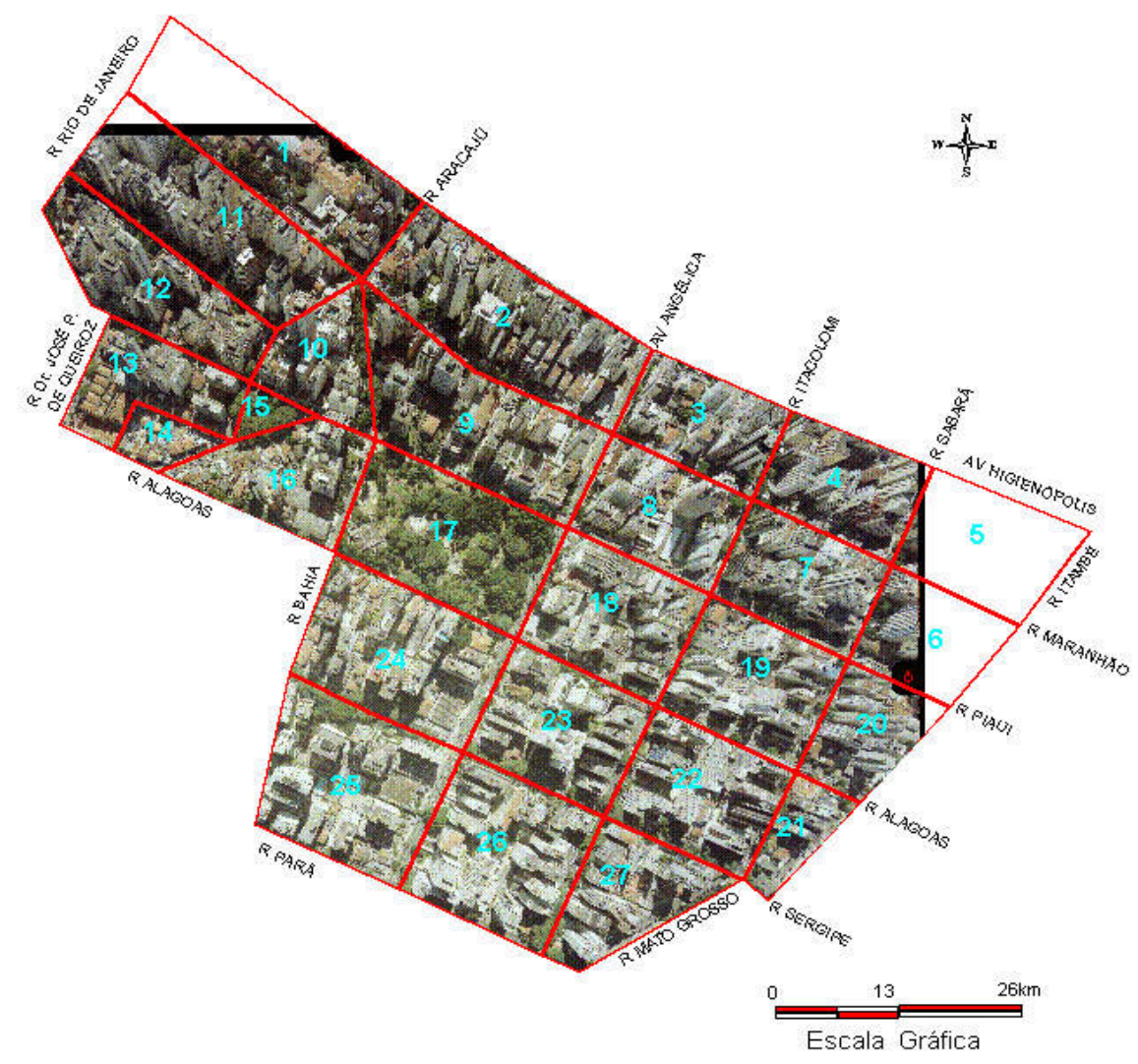


ANEXO B

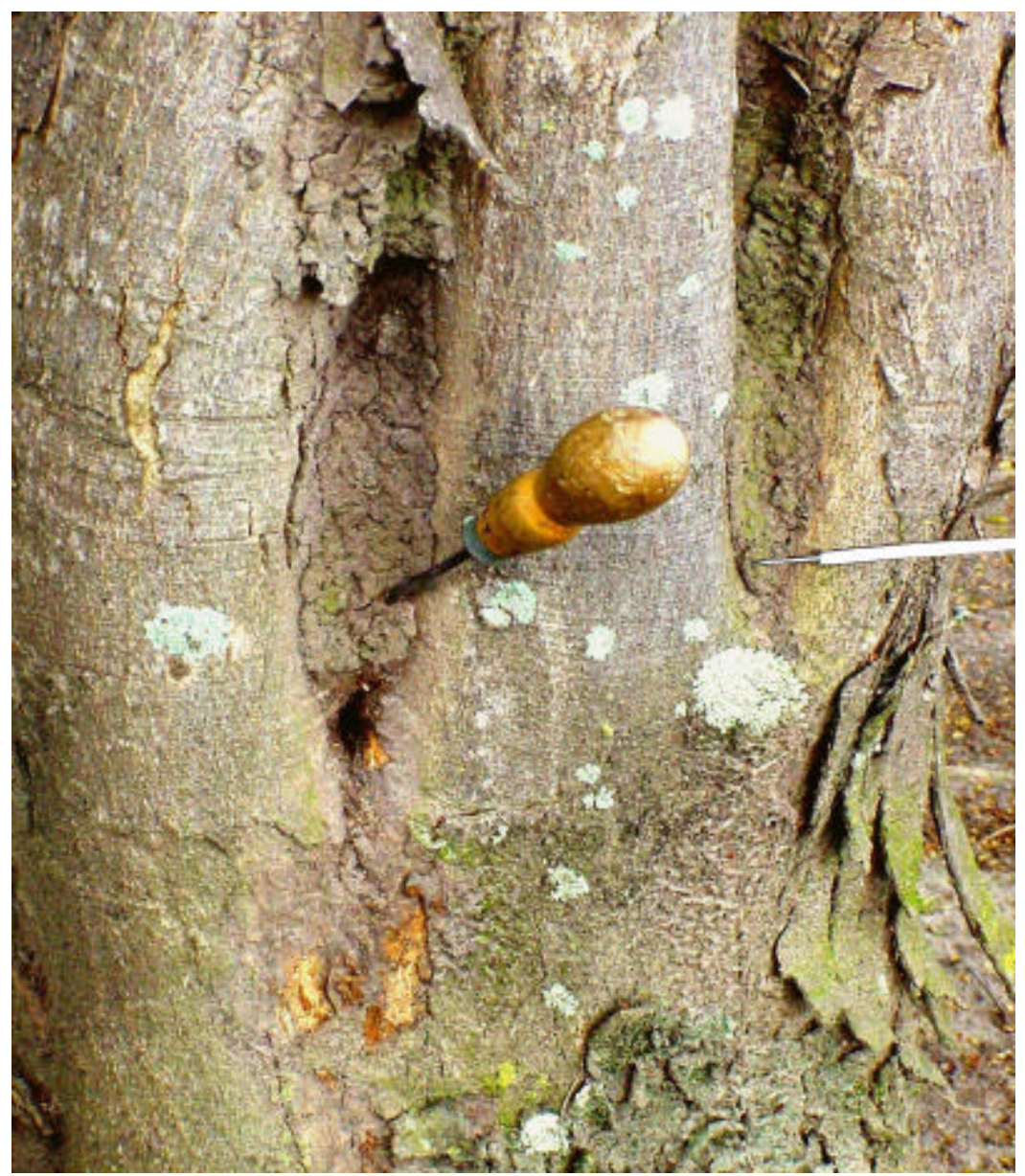

Figura 4 - Túneis de cupins-subterrâneos em reentrâncias de Caesalpinia peltophoroides. 


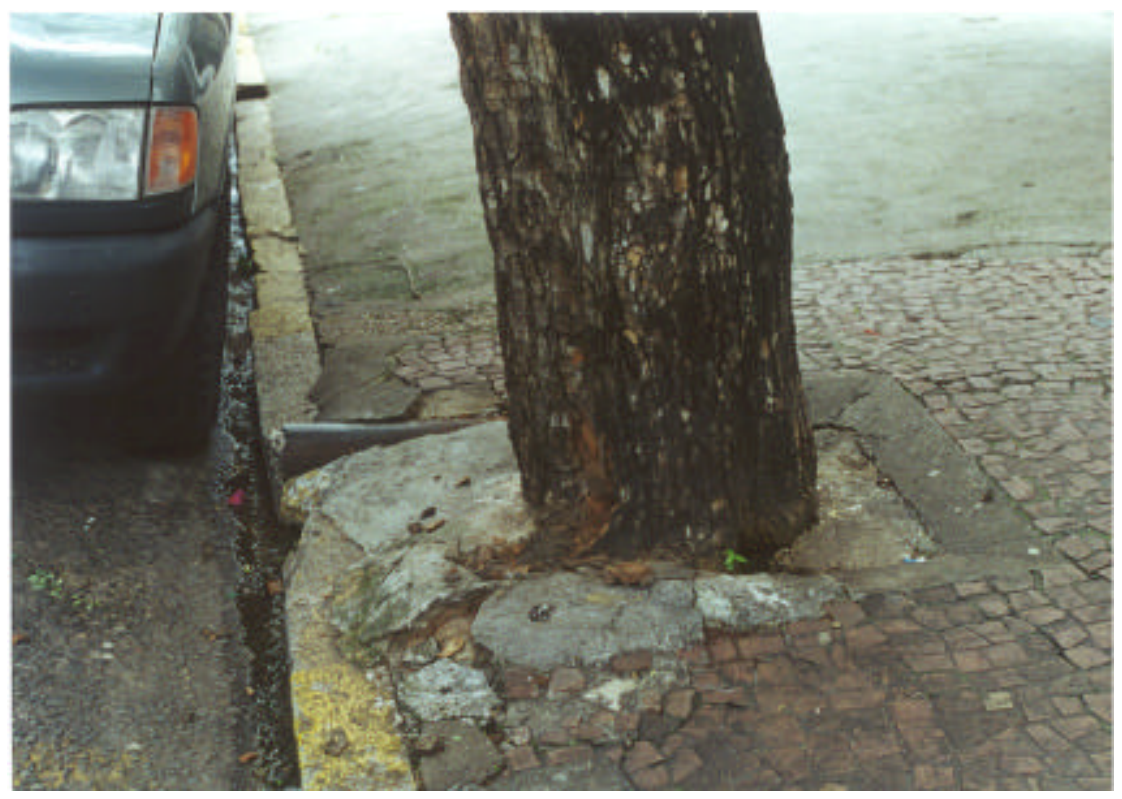

Figura 5 - Calçamento inadequado. 


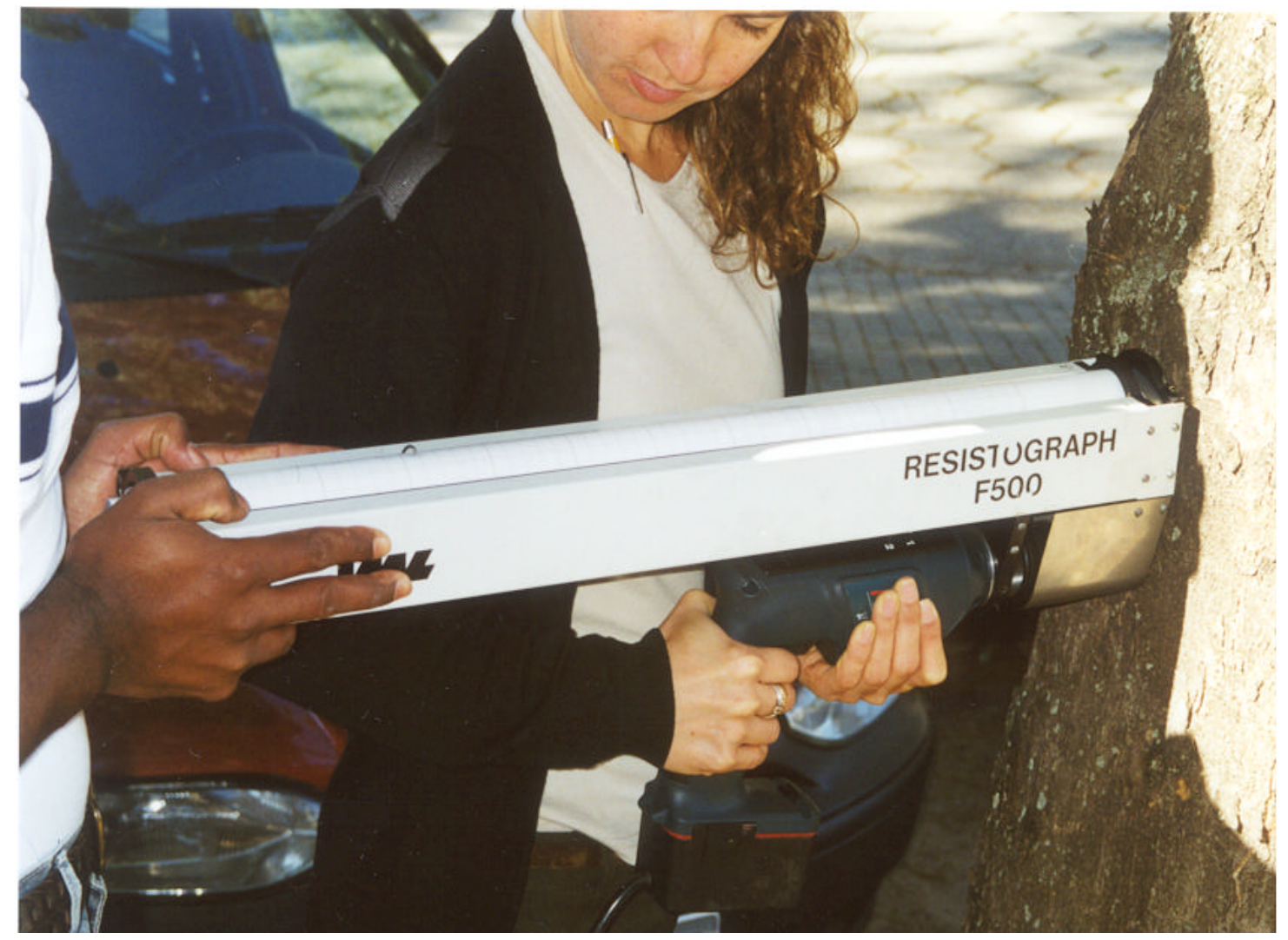

Figura 6 - Teste com o equipamento Resistógrafo ${ }^{\circledR}$. 


\section{ANEXO C}

Gráficos das prospecções internas com as três classes de decaimento

1. Nenhum decaimento

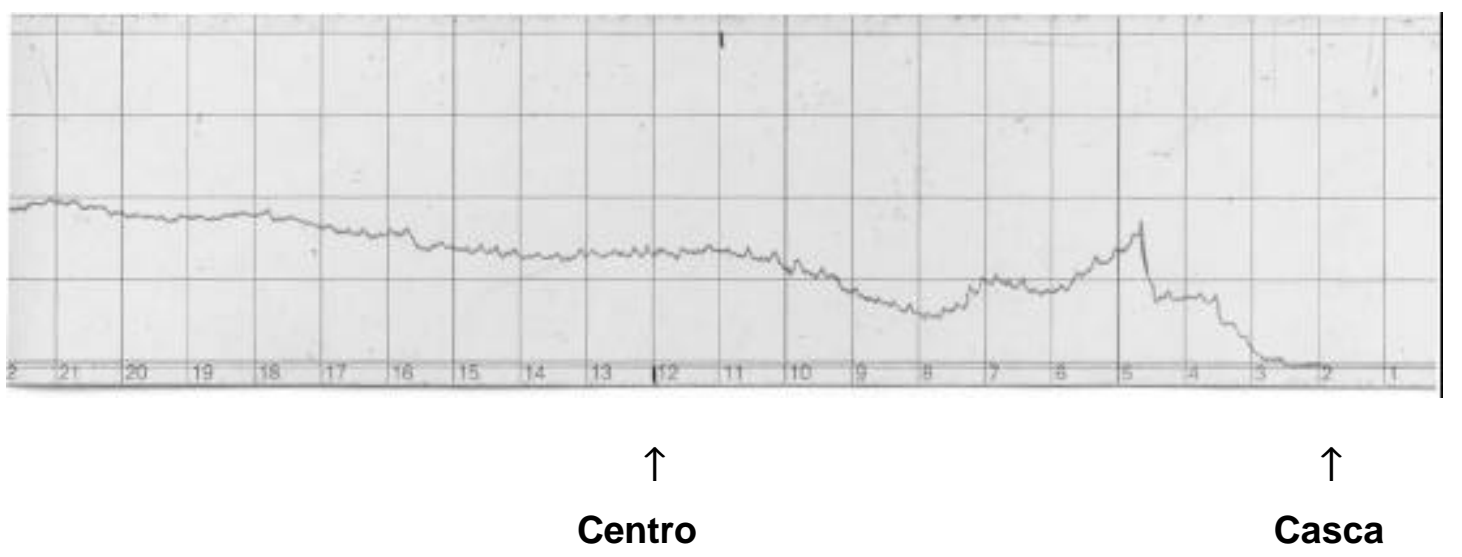

Distâncias em cm

Figura 7 - Árvore alfeneiro, registrada com o número 10, na Tabela 1.

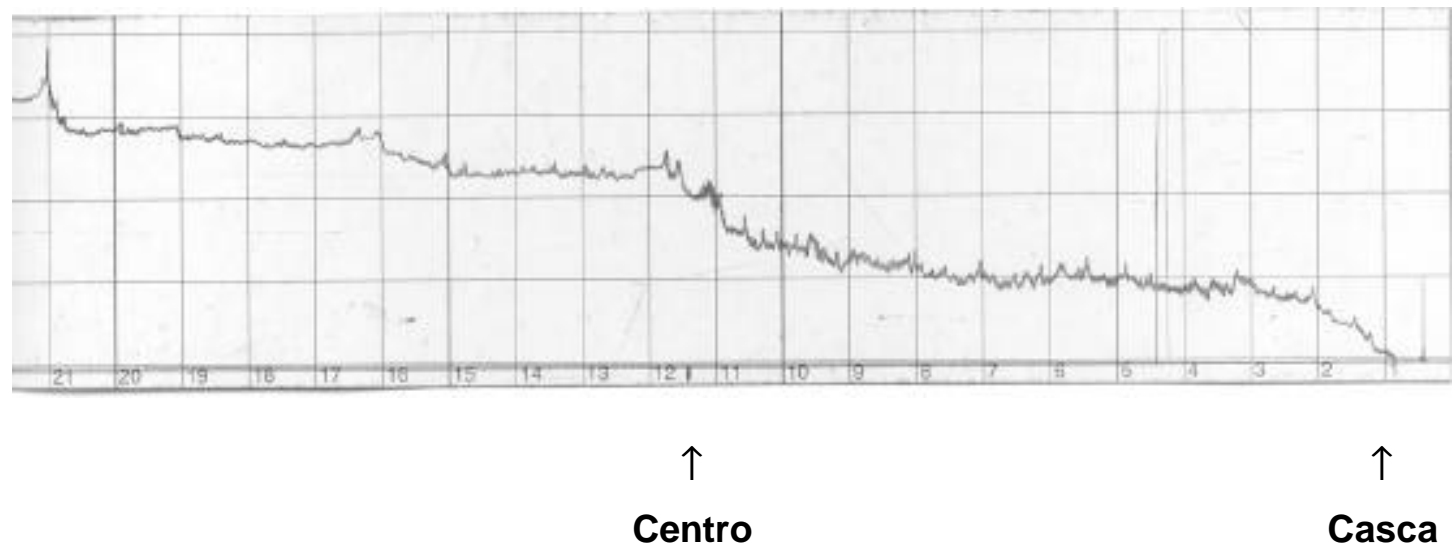

Distâncias em cm

Figura 8 - Árvore alfeneiro, registrada com o número 04, na Tabela 1. 


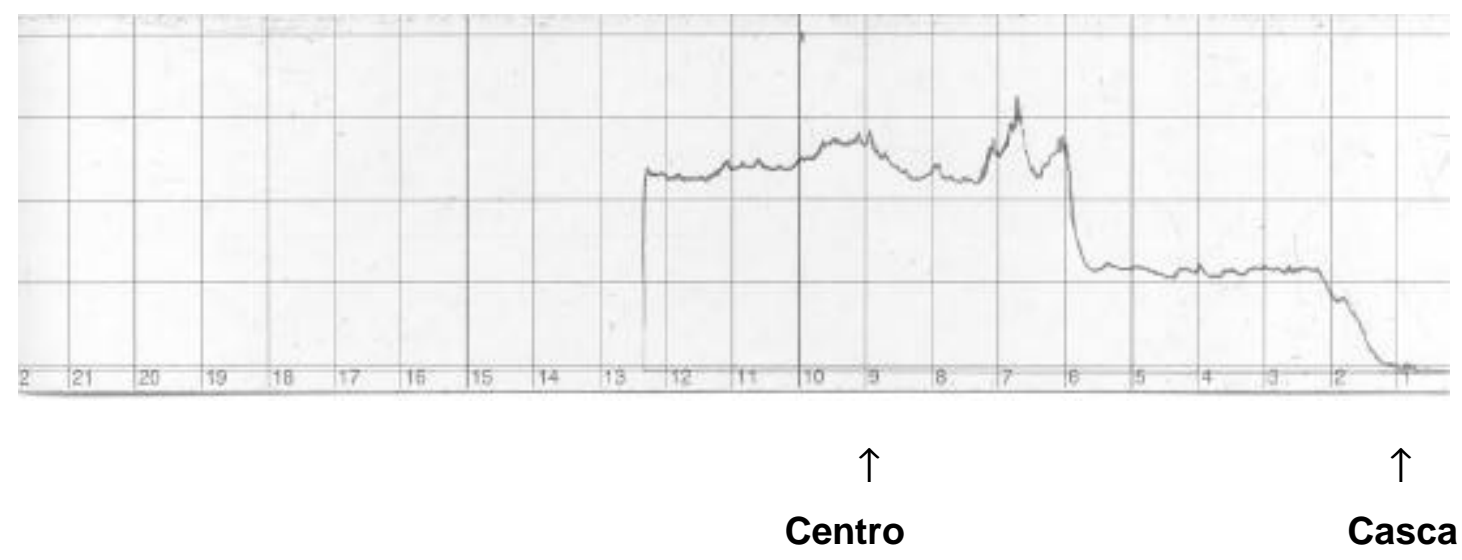

Distâncias em cm

Figura 9 - Árvore sibipiruna, registrada com o número 34, na Tabela 1.

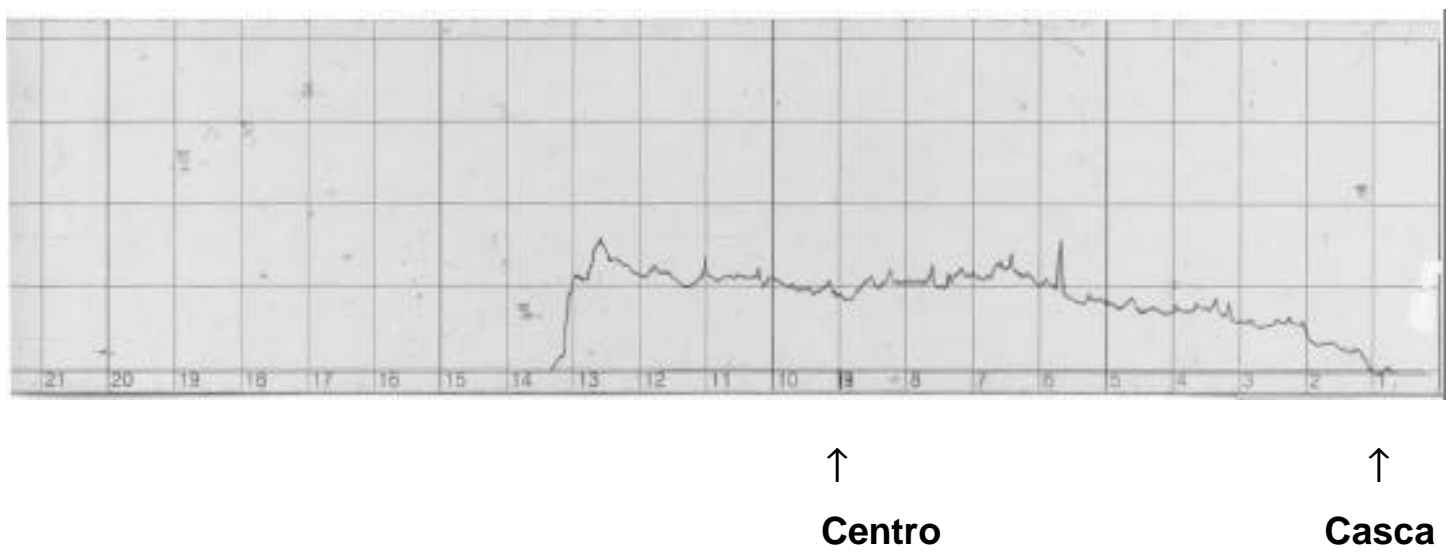

Distâncias em cm

Figura 10 - Árvore ficus, registrada com o número 45, na Tabela 1. 


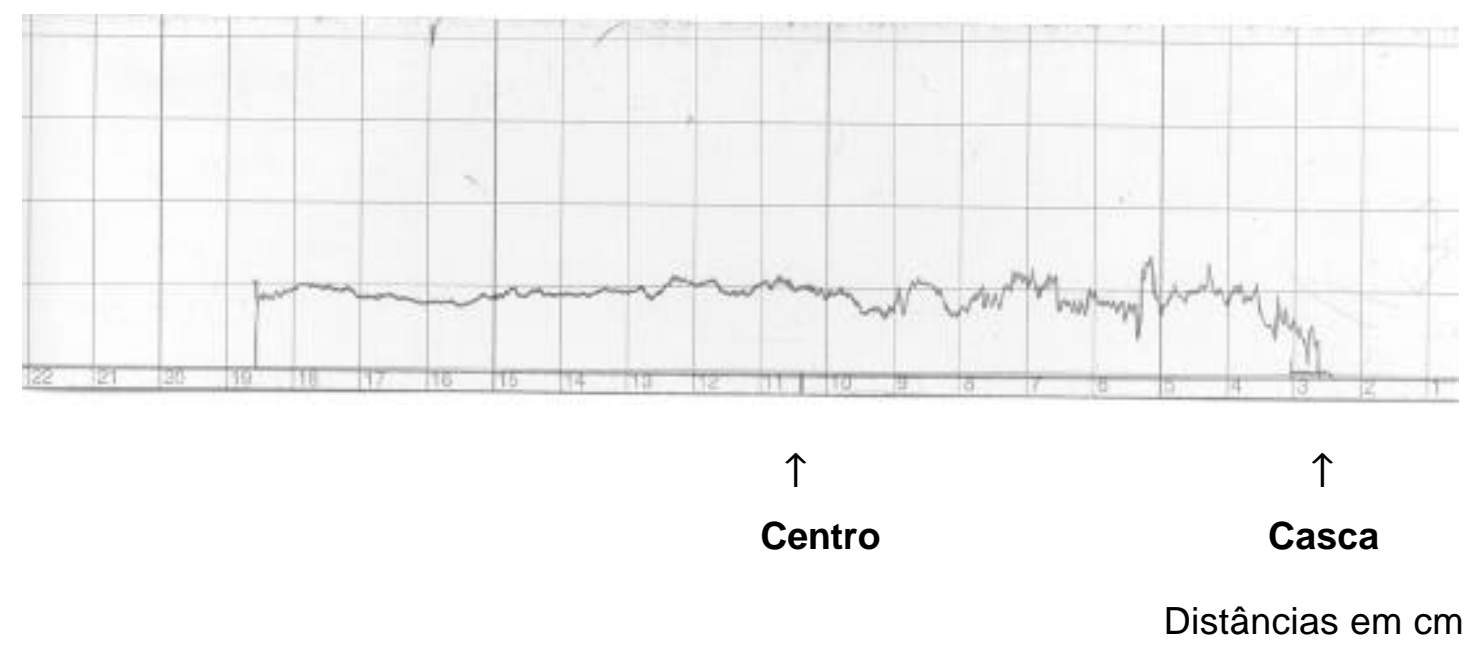

Figura 11 - Árvore mamorana, registrada com o número 25, na Tabela 1. 
2. Decaimento leve a moderado

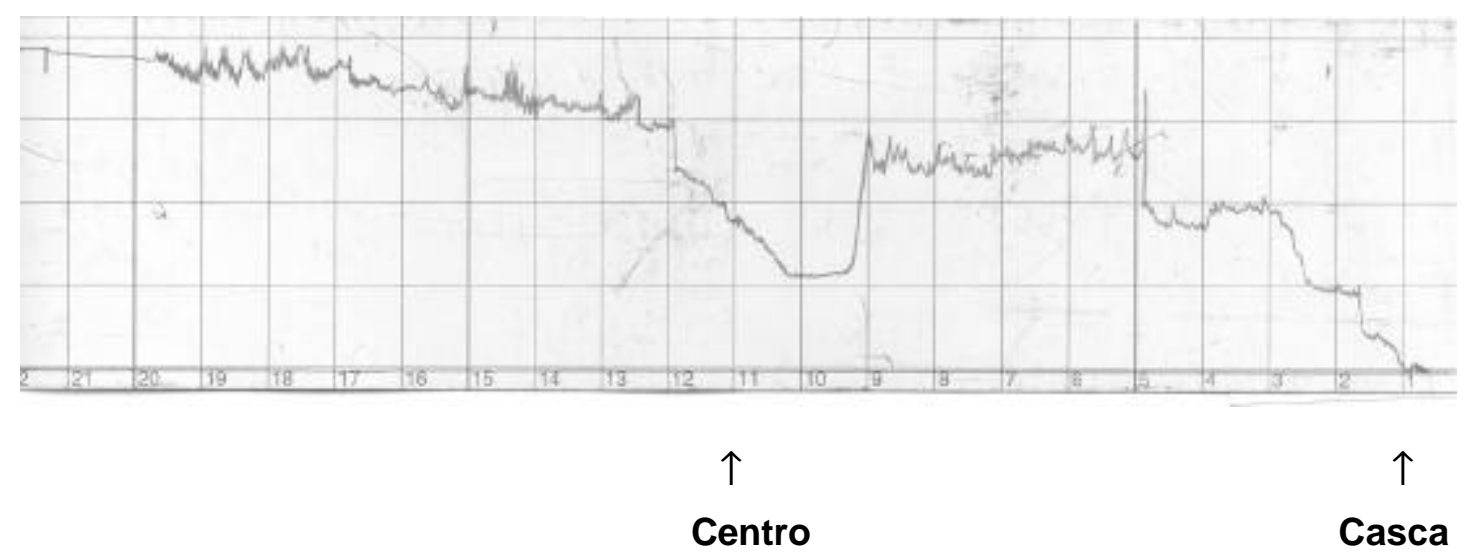

Distâncias em cm

Figura 12 - Árvore sibipiruna, registrada com o número 01, na Tabela 1.

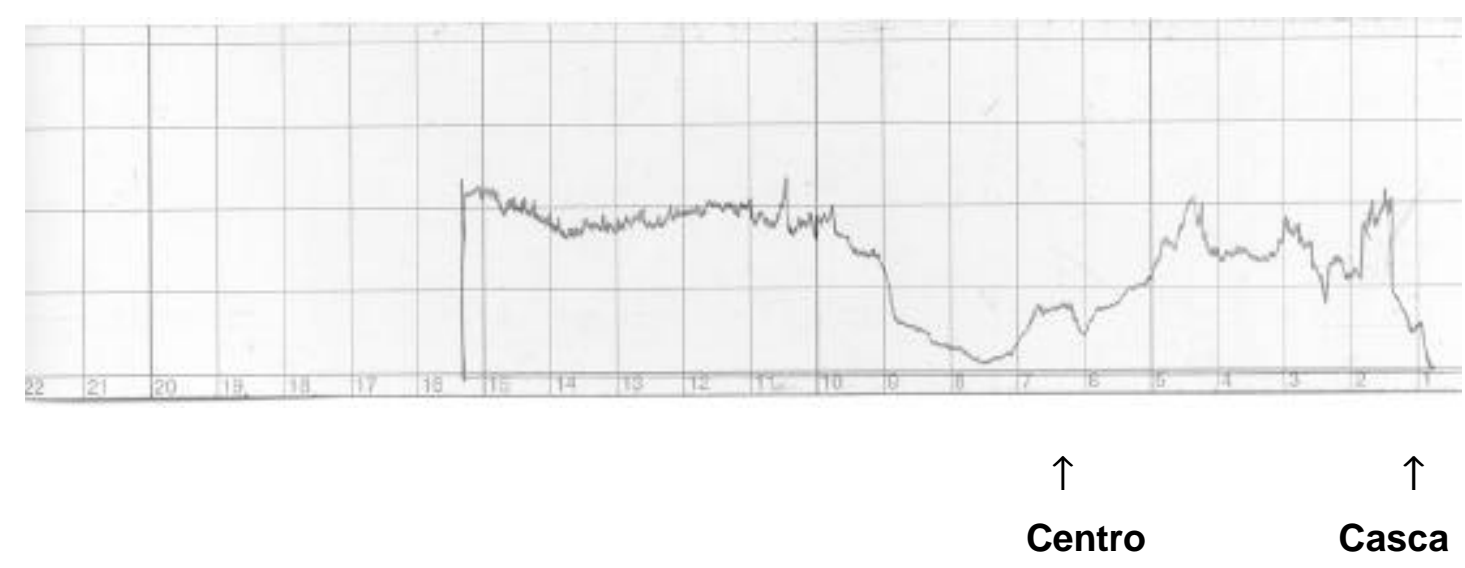

Distâncias em cm

Figura 13 - Árvore quaresmeira, registrada com o número 13, na Tabela 1. 


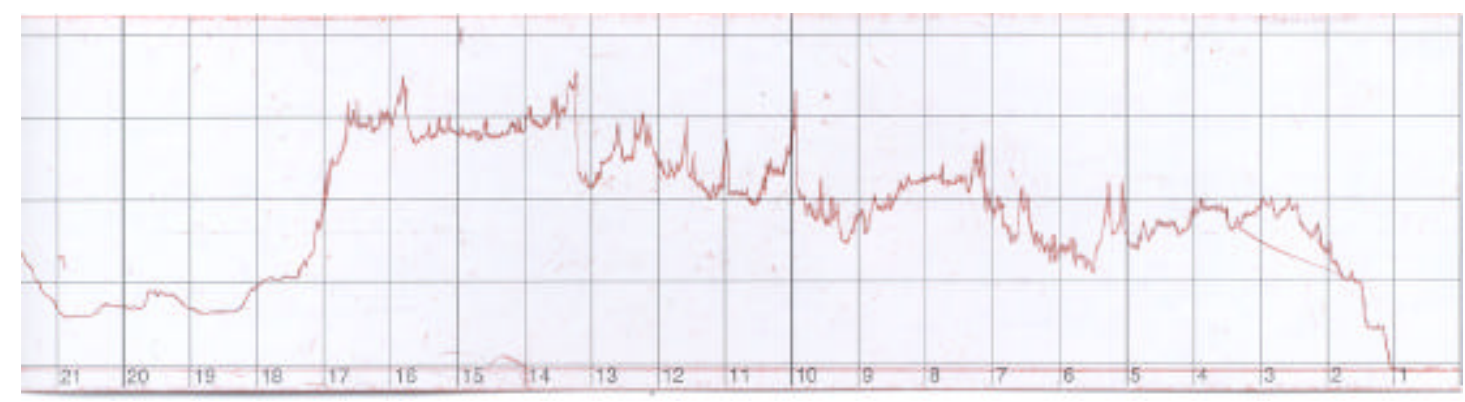

$\uparrow$ $\uparrow$

Centro

Casca

Distâncias em cm

Figura 14 - Árvore tipuana, registrada com o número 36, na Tabela 1.

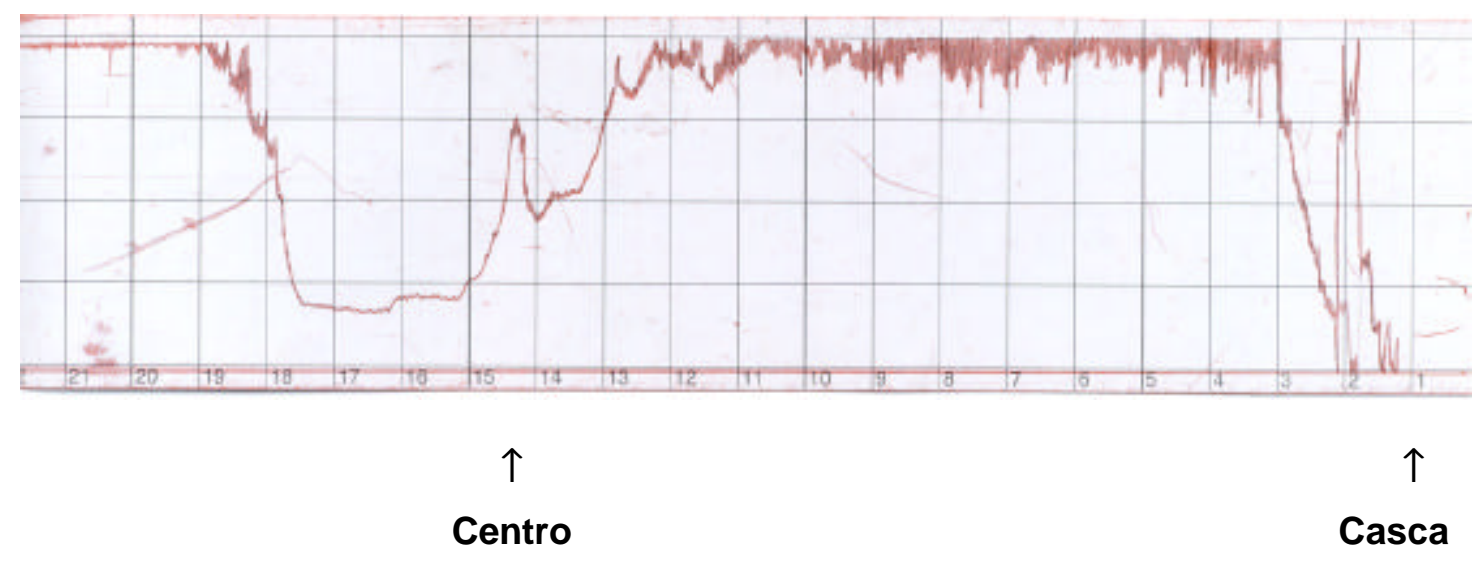

Distâncias em cm

Figura 15 - Árvore alfeneiro, registrada com o número 08, na Tabela 1. 


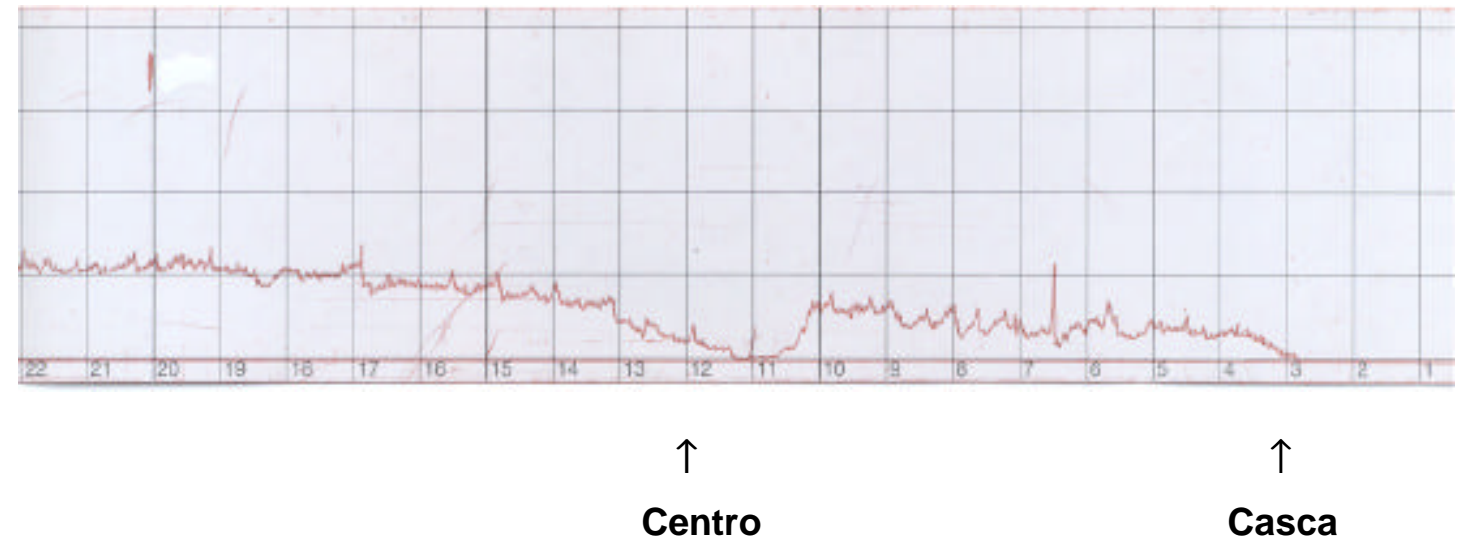

Distâncias em cm

Figura 16 - Árvore espatódea, registrada com o número 29, na Tabela 1. 
1 Decaimento intenso

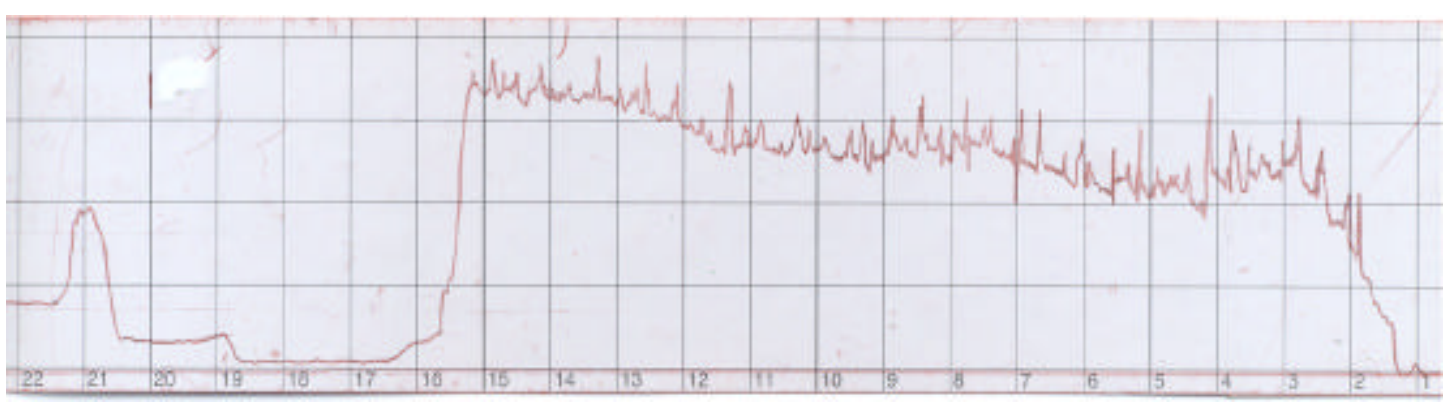

$\uparrow$ $\uparrow$

Centro

Casca

Distâncias em cm

Figura 17 - Árvore alfeneiro, registrada com o número 14, na Tabela 1.

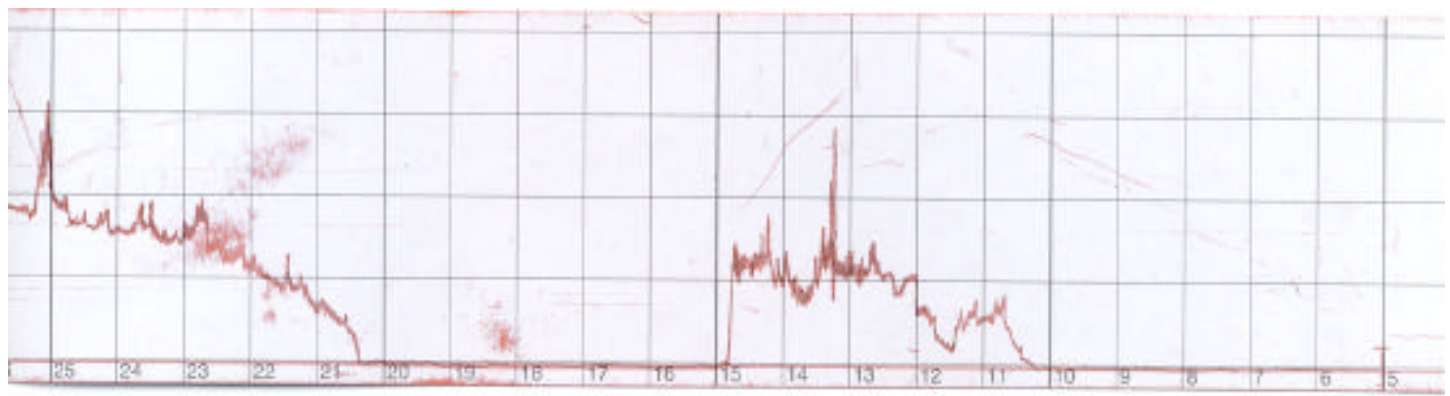

$\uparrow$

$\uparrow$

Centro

Casca

Distâncias em cm

Figura 18 - Árvore alfeneiro, registrada com o número 18, na Tabela 1. 


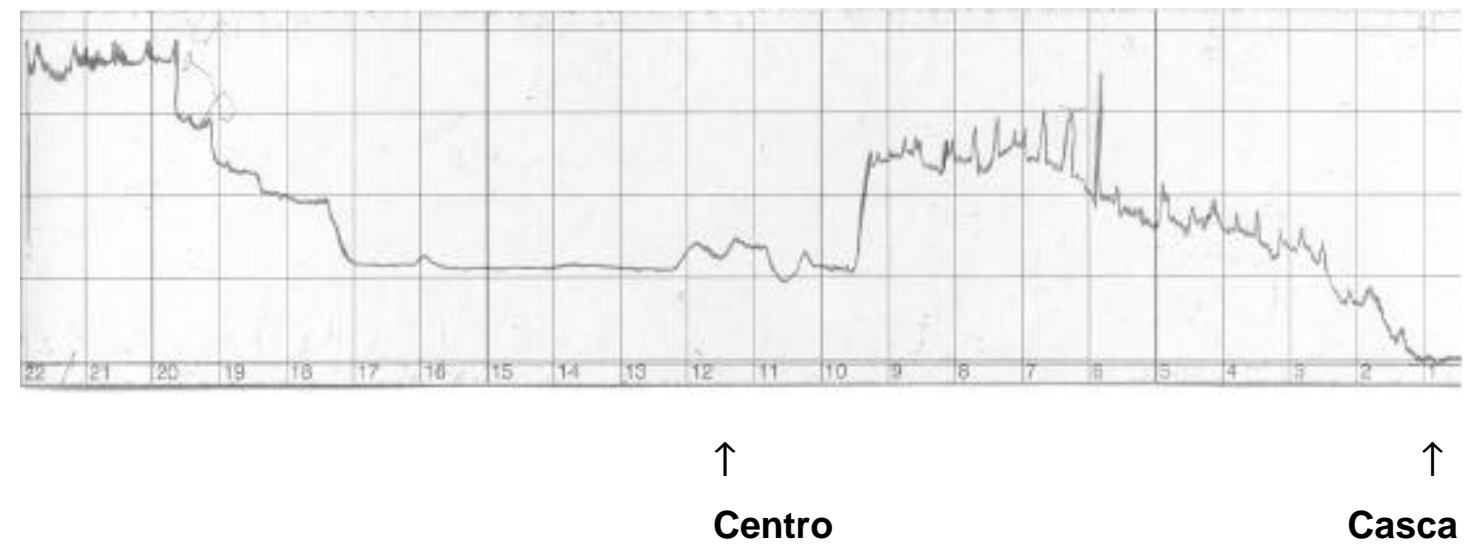

Distâncias em cm

Figura 19 - Árvore sibipiruna, registrada com o número 23, na Tabela 1.

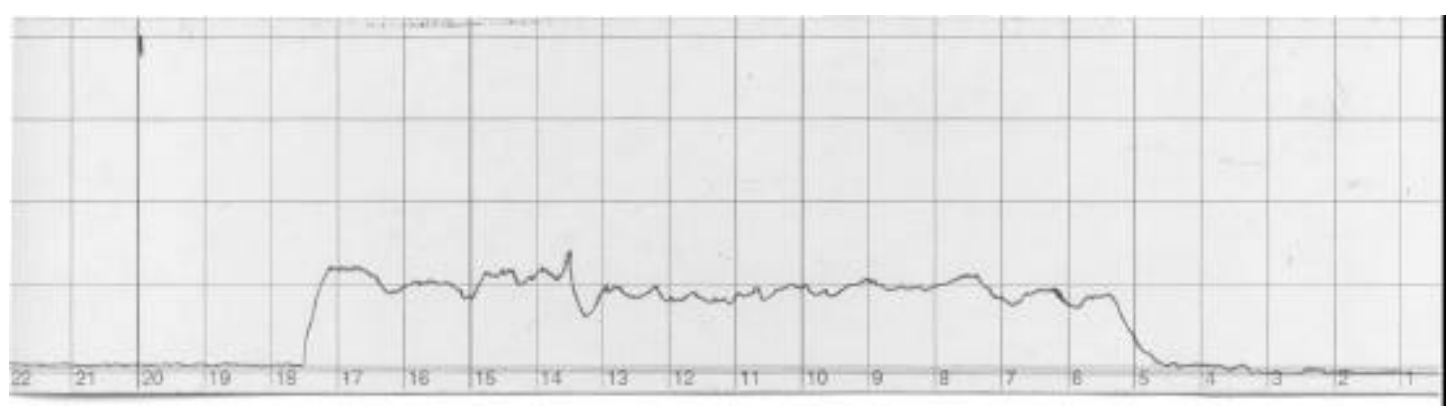

$\uparrow$ $\uparrow$

Centro

Casca

Distâncias em cm

Figura 20 - Árvore tipuana, registrada com o número 33, na Tabela 1. 


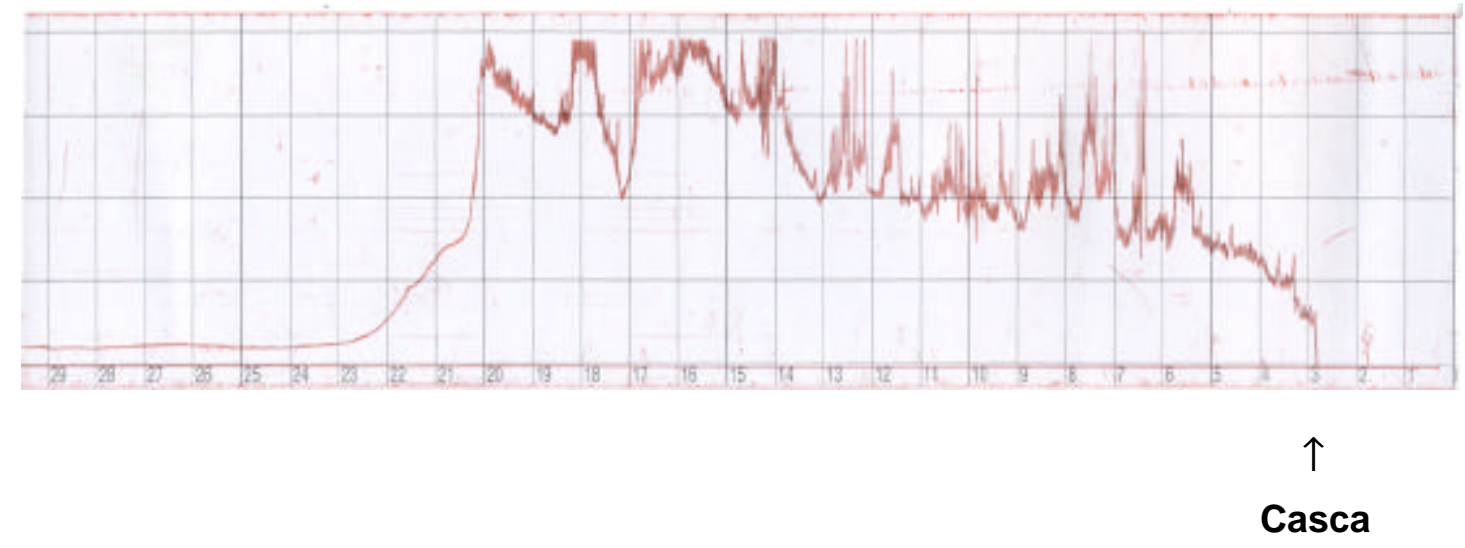

Distâncias em cm

Figura 21 - Árvore ficus, registrada com o número 12, na Tabela 1. 


\section{ANEXO D}

\section{ANÁLISE ESTATÍSTICA}

\subsection{Recodificação dos dados}

Como observado na Planilha 1, anteriormente apresentada, foram considerados os seguintes indicadores:
A. análise externa do tronco (An. Ext.);
B. condições gerais da árvore (Cond. Ger.);
C. condições de entorno (Cond. Ent.);
D. prospecção interna (Prosp. Int.); e
E. análise interna (An. Int.).

Para cada um destes indicadores foram incorporados vários atributos objetivando enriquecer as informações durante o diagnóstico das árvores nos trabalhos de campo. Tendo em vista o grande número de atributos em cada indicador e, conseqüentemente, o correspondente código para cada um, verificou-se a dificuldade que o elevado número de códigos traria para a análise estatística dos dados. Sendo assim, fez-se uma simplificação da matriz original, com todos os atributos e seus respectivos códigos, para uma matriz indicadora, ou seja, composta por zeros ou uns, dependendo se um determinado atributo estava ou não presente na árvore analisada, conforme Tabela 2. Assim por exemplo, para o caso do indicador A, que reúne os atributos que caracterizaram a análise externa do tronco, todos os códigos foram substituídos pelo número zero, quando a árvore não apresentasse sinais ou presença de cupins, ou 1 se apresentasse. 
Tabela 2. Matriz indicadora 0 e 1

\begin{tabular}{|c|c|c|c|c|c|c|c|c|c|c|c|c|c|c|c|c|}
\hline N.. & $A^{1}$ & B & C & D & $E$ & $F$ & $G$ & $\mathrm{H}$ & I & $\mathrm{J}$ & K & L & $M$ & $\mathrm{~N}$ & 0 & $P$ \\
\hline 1 & 0 & 1 & 0 & 0 & 1 & 0 & 0 & 0 & 0 & 0 & 1 & 0 & 0 & 0 & 1 & 0 \\
\hline 2 & 1 & 1 & 1 & 0 & 0 & 0 & 0 & 0 & 0 & 0 & 0 & 0 & 1 & 0 & 1 & 0 \\
\hline 3 & 0 & 0 & 0 & 1 & 1 & 0 & 0 & 1 & 1 & 0 & 1 & 0 & 0 & 0 & 0 & 0 \\
\hline 4 & 0 & 0 & 1 & 0 & 0 & 0 & 1 & 0 & 0 & 1 & 0 & 0 & 1 & 0 & 0 & 0 \\
\hline 5 & 0 & 0 & 1 & 0 & 0 & 0 & 1 & 0 & 0 & 0 & 1 & 0 & 0 & 0 & 0 & 0 \\
\hline 6 & 0 & 0 & 0 & 0 & 1 & 0 & 0 & 1 & 0 & 0 & 1 & 0 & 0 & 1 & 0 & 0 \\
\hline 7 & 0 & 0 & 0 & 0 & 0 & 0 & 1 & 1 & 0 & 0 & 1 & 0 & 0 & 0 & 0 & 0 \\
\hline 8 & 1 & 0 & 1 & 0 & 0 & 1 & 0 & 0 & 0 & 1 & 0 & 1 & 0 & 0 & 1 & 0 \\
\hline 9 & 0 & 1 & 1 & 0 & 0 & 0 & 1 & 0 & 0 & 0 & 1 & 0 & 0 & 0 & 0 & 0 \\
\hline 10 & 0 & 1 & 0 & 0 & 1 & 0 & 0 & 0 & 0 & 1 & 0 & 0 & 1 & 0 & 0 & 0 \\
\hline 11 & 0 & 0 & 0 & 0 & 0 & 0 & 1 & 0 & 0 & 1 & 0 & 1 & 0 & 0 & 0 & 0 \\
\hline 12 & 1 & 0 & 1 & 0 & 0 & 0 & 1 & 1 & 1 & 0 & 0 & 0 & 1 & 0 & 1 & 1 \\
\hline 13 & 0 & 0 & 1 & 0 & 0 & 0 & 0 & 1 & 0 & 1 & 0 & 0 & 1 & 0 & 1 & 0 \\
\hline 14 & 0 & 0 & 0 & 0 & 0 & 0 & 1 & 1 & 0 & 0 & 0 & 0 & 1 & 0 & 1 & 0 \\
\hline 15 & 0 & 1 & 0 & 1 & 1 & 0 & 0 & 0 & 0 & 0 & 1 & 0 & 0 & 0 & 0 & 0 \\
\hline 16 & 0 & 0 & 1 & 0 & 1 & 0 & 0 & 0 & 0 & 0 & 1 & 0 & 0 & 0 & 0 & 0 \\
\hline 17 & 0 & 0 & 0 & 0 & 0 & 0 & 1 & 0 & 1 & 0 & 1 & 0 & 0 & 0 & 0 & 0 \\
\hline 18 & 1 & 0 & 0 & 0 & 0 & 0 & 1 & 0 & 0 & 1 & 0 & 0 & 1 & 0 & 1 & 1 \\
\hline 19 & 0 & 1 & 1 & 0 & 1 & 0 & 0 & 0 & 0 & 0 & 0 & 0 & 1 & 0 & 0 & 0 \\
\hline 20 & 0 & 0 & 1 & 1 & 1 & 0 & 0 & 0 & 0 & 0 & 1 & 0 & 0 & 0 & 0 & 0 \\
\hline 21 & 0 & 0 & 1 & 0 & 0 & 0 & 1 & 1 & 0 & 0 & 1 & 0 & 0 & 0 & 0 & 0 \\
\hline 22 & 0 & 1 & 0 & 0 & 1 & 0 & 0 & 0 & 0 & 1 & 0 & 1 & 0 & 1 & 0 & 0 \\
\hline 23 & 1 & 1 & 1 & 0 & 0 & 0 & 1 & 0 & 1 & 1 & 0 & 0 & 1 & 0 & 1 & 1 \\
\hline 24 & 1 & 1 & 1 & 0 & 0 & 0 & 1 & 0 & 0 & 1 & 0 & 0 & 1 & 0 & 1 & 1 \\
\hline 25 & 0 & 1 & 1 & 0 & 0 & 0 & 0 & 0 & 0 & 0 & 1 & 0 & 0 & 0 & 0 & 0 \\
\hline 26 & 1 & 0 & 1 & 0 & 0 & 0 & 1 & 0 & 0 & 0 & 0 & 0 & 1 & 0 & 1 & 1 \\
\hline 27 & 0 & 0 & 0 & 0 & 0 & 0 & 1 & 0 & 1 & 0 & 0 & 0 & 1 & 0 & 0 & 0 \\
\hline 28 & 0 & 0 & 0 & 1 & 0 & 0 & 1 & 0 & 0 & 1 & 0 & 0 & 1 & 0 & 1 & 1 \\
\hline 29 & 0 & 0 & 0 & 0 & 0 & 0 & 1 & 0 & 0 & 1 & 0 & 0 & 1 & 0 & 1 & 0 \\
\hline 30 & 1 & 0 & 0 & 0 & 0 & 0 & 1 & 0 & 0 & 0 & 0 & 1 & 0 & 0 & 0 & 0 \\
\hline 31 & 1 & 0 & 1 & 1 & 0 & 0 & 1 & 1 & 0 & 0 & 0 & 0 & 1 & 0 & 1 & 0 \\
\hline 32 & 1 & 0 & 0 & 0 & 0 & 0 & 1 & 1 & 0 & 0 & 0 & 0 & 1 & 0 & 1 & 1 \\
\hline 33 & 0 & 0 & 0 & 0 & 0 & 0 & 1 & 0 & 1 & 0 & 0 & 1 & 0 & 0 & 1 & 1 \\
\hline 34 & 0 & 0 & 1 & 0 & 1 & 0 & 0 & 0 & 0 & 0 & 1 & 0 & 0 & 0 & 0 & 0 \\
\hline 35 & 0 & 1 & 0 & 0 & 0 & 0 & 1 & 0 & 0 & 1 & 0 & 0 & 1 & 0 & 1 & 0 \\
\hline 36 & 0 & 1 & 1 & 0 & 0 & 1 & 0 & 0 & 0 & 1 & 1 & 0 & 0 & 0 & 1 & 0 \\
\hline 37 & 0 & 0 & 1 & 0 & 0 & 0 & 1 & 1 & 0 & 0 & 1 & 0 & 0 & 0 & 0 & 0 \\
\hline 38 & 0 & 0 & 1 & 0 & 0 & 0 & 1 & 1 & 0 & 0 & 1 & 0 & 0 & 0 & 0 & 0 \\
\hline 39 & 0 & 0 & 1 & 0 & 0 & 0 & 1 & 0 & 0 & 1 & 0 & 0 & 1 & 0 & 0 & 0 \\
\hline 40 & 0 & 0 & 0 & 0 & 0 & 0 & 1 & 0 & 0 & 0 & 0 & 0 & 1 & 0 & 0 & 0 \\
\hline 41 & 0 & 0 & 1 & 0 & 0 & 0 & 1 & 0 & 0 & 1 & 1 & 0 & 0 & 0 & 0 & 0 \\
\hline 42 & 0 & 0 & 0 & 0 & 0 & 0 & 1 & 0 & 0 & 0 & 1 & 0 & 0 & 0 & 0 & 0 \\
\hline 43 & 0 & 0 & 1 & 0 & 0 & 0 & 1 & 0 & 1 & 1 & 0 & 0 & 1 & 0 & 1 & 1 \\
\hline 44 & 0 & 0 & 0 & 0 & 0 & 0 & 1 & 0 & 1 & 0 & 0 & 0 & 1 & 0 & 0 & 0 \\
\hline 45 & 0 & 1 & 1 & 0 & 1 & 0 & 0 & 0 & 0 & 1 & 1 & 0 & 0 & 0 & 0 & 0 \\
\hline 46 & 0 & 0 & 1 & 1 & 1 & 0 & 0 & 0 & 0 & 1 & 1 & 0 & 0 & 0 & 0 & 0 \\
\hline 47 & 0 & 0 & 0 & 0 & 0 & 0 & 1 & 0 & 0 & 1 & 1 & 0 & 0 & 0 & 1 & 0 \\
\hline 48 & 0 & 0 & 1 & 0 & 0 & 0 & 1 & 0 & 0 & 0 & 0 & 1 & 0 & 0 & 1 & 0 \\
\hline 49 & 1 & 0 & 0 & 0 & 0 & 0 & 1 & 0 & 0 & 1 & 0 & 1 & 0 & 0 & 0 & 0 \\
\hline
\end{tabular}

Legenda dos itens: A, An. Ext.; B, Sad.; C, Fer.; D, Rach.; E, P.L.; F, P.D.; G, P.M.; H, Doen.; I, Oco; J, Reen.; K, Esp. Ad.; L, Esp. In.; M, Esp. Rest.; N, Duas Árv.; O, Prosp. Int. e P, An. Int. 
Para os outros indicadores, ou seja, de B a E, manteve-se os atributos de análise. No entanto, foram codificados também como zero ou um a ausência ou presença do atributo na árvore. Por exemplo, para o grupo $\mathrm{B}$, se a árvore apresentasse aspecto de sadia, codificou-se como 1, caso contrário, zero. Assim, da mesma forma, para os demais atributos dos outros indicadores.

A análise estatística dos dados foi realizada na matriz indicadora montada como acima descrito. Tendo em vista a característica dessa matriz, de ser composta apenas por zeros e uns, portanto em uma escala nominal, e de existir um certo grau de multicolinearidade, como pode ser observado na matriz de correlação entre as variáveis independentes, mostrada na Tabela 3, optou-se pela análise de regressão múltipla via componentes principais dessas variáveis, como descrita por Jolliffe (1986).

Tabela 3. Matriz de correlação entre as variáveis independentes.

\begin{tabular}{|c|c|c|c|c|c|c|c|c|c|c|}
\hline Variáveis & An. Ext. & Sad. & Fer. & Rach. & P. L. & P. D. & P. M. & Doen. & Oco & Reen \\
\hline An. Ext. & 1,00 & 0,01 & 0,11 & $-0,05$ & $-0,31^{*}$ & 0,14 & 0,19 & 0,06 & 0,03 & 0,05 \\
\hline Sad. & & 1,00 & 0,10 & $-0,08$ & $0,30^{*}$ & 0,11 & $-0,44^{*}$ & $-0,32^{*}$ & $-0,14$ & 0,16 \\
\hline Fer. & & & 1,00 & $-0,02$ & $-0,03^{*}$ & 0,19 & $-0,17$ & 0,02 & $-0,14$ & 0,03 \\
\hline Rach. & & & & 1,00 & $0,37^{*}$ & $-0,08$ & $-0,25$ & 0,10 & 0,00 & $-0,06$ \\
\hline P. L. & & & & & 1,00 & $-0,12$ & $-0,78^{*}$ & $-0,08$ & $-0,12$ & $-0,09$ \\
\hline P. D. & & & & & & 1,00 & $0,28^{*}$ & $-0,11$ & $-0,09$ & 0,25 \\
\hline P. M. & & & & & & & 1,00 & 0,08 & 0,21 & $-0,01$ \\
\hline Doen. & & & & & & & & 1,00 & 0,03 & $-0,35^{\star}$ \\
\hline Oco & & & & & & & & & 1,00 & $-0,14$ \\
\hline Reen. & & & & & & & & & & 1,00 \\
\hline \multicolumn{11}{|l|}{ Esp. Ad. } \\
\hline \multicolumn{11}{|l|}{ Esp. In. } \\
\hline \multicolumn{11}{|l|}{$\begin{array}{l}\text { Esp. } \\
\text { Rest. }\end{array}$} \\
\hline Duas Árv. & & & & & & & & & & \\
\hline
\end{tabular}




\subsection{Componentes Principais}

Da análise de componentes principais das variáveis independentes foram extraídos 13 componentes pelo processo VARIMAX de rotação. Estes componentes são mostrados na Tabela 4.

Tabela 4. Resultados da análise de componentes principais

\begin{tabular}{lccccccc} 
& \multicolumn{1}{c}{ CP $^{1} 1$} & CP 2 & CP 3 & CP 4 & CP 5 & CP 6 & CP 7 \\
\hline Variáveis & P.L. & Doen. & Esp. In. & $\begin{array}{c}\text { Esp. Ad. } \\
\text { Esp. Rest. }\end{array}$ & P.D. & Rach. & Oco \\
& P.M. & & & & \\
\hline An. Ext. & $-0,12968$ & 0,045234 & $-0,11089$ & $-0,25169$ & $-0,07666$ & 0,001201 & 0,000316 \\
Sad. & 0,234775 & $-0,16571$ & 0,075069 & $-0,02007$ & $-0,04588$ & 0,064901 & 0,061522 \\
Fer. & 0,040192 & 0,012853 & 0,101552 & 0,051455 & $-0,09422$ & 0,021154 & 0,066237 \\
Rach. & 0,197518 & 0,046809 & 0,067695 & 0,059944 & 0,038968 & $-0,97025^{*}$ & $-0,00816$ \\
P.L. & $0,881578^{*}$ & $-0,05951$ & 0,044173 & 0,188253 & 0,145157 & $-0,19695$ & 0,035055 \\
P.D. & 0,044723 & $-0,0357$ & $-0,10449$ & 0,075137 & $-0,97213^{*}$ & 0,040747 & 0,032163 \\
P.M. & $-0,87634^{*}$ & 0,015919 & $-0,0164$ & $-0,14065$ & 0,22851 & 0,104452 & $-0,09432$ \\
Doen. & $-0,05192$ & $0,955657^{*}$ & 0,120878 & 0,024906 & 0,036392 & $-0,04805$ & $-0,00255$ \\
Oco & $-0,07951$ & 0,002898 & 0,011363 & $-0,09656$ & 0,031443 & $-0,00753$ & $-0,98454^{*}$ \\
Reen. & $-0,0276$ & $-0,17083$ & $-0,05373$ & $-0,16668$ & $-0,12953$ & 0,009438 & 0,080633 \\
Esp. Ad. & 0,171575 & 0,062534 & 0,32752 & $0,884119^{*}$ & $-0,01647$ & $-0,07163$ & 0,069613 \\
Esp. In. & $-0,04339$ & $-0,12029$ & $-0,9596^{*}$ & 0,021651 & $-0,1081$ & 0,071526 & 0,011698 \\
Esp. Rest. & $-0,14089$ & 0,022525 & 0,351019 & $-0,89943^{*}$ & 0,092913 & 0,021051 & $-0,07789$ \\
Duas Árv. & 0,207421 & 0,093718 & $-0,11692$ & 0,046134 & 0,030976 & 0,062802 & 0,039088 \\
Variância & 1,763697 & 1,007074 & 1,228573 & 1,761818 & 1,077332 & 1,014484 & 1,007798 \\
explicada & & & & & & & \\
Prp.Totl & 0,125978 & 0,071934 & 0,087755 & 0,125844 & 0,076952 & 0,072463 & 0,071986 \\
\hline CP - Componente principal & & & & & &
\end{tabular}


Tabela 4. Resultados da análise de componentes principais

\begin{tabular}{lcccccc}
\cline { 2 - 6 } & CP 8 & CP 9 & CP 10 & CP 11 & CP 12 & CP 13 \\
\cline { 1 - 6 } Variáveis & Reen. & Fer. & An. Ext. & Sad. & Duas Árv. & \\
\hline An. Ext. & $-0,00292$ & $-0,07121$ & $0,944527^{*}$ & 0,023772 & 0,042903 & 0,001644 \\
Sad. & 0,066755 & $-0,04354$ & 0,024582 & $0,944604^{*}$ & $-0,04521$ & 0,001593 \\
Fer. & 0,016462 & $-0,97645^{*}$ & 0,06396 & 0,040418 & 0,109895 & 0,005026 \\
Rach. & $-0,00923$ & 0,021073 & $-0,00126$ & $-0,05974$ & 0,059635 & $-0,00119$ \\
P.L. & $-0,03458$ & 0,043963 & $-0,12399$ & 0,109103 & $-0,18229$ & $-0,2391$ \\
P.D. & 0,123886 & $-0,09528$ & 0,071547 & 0,042961 & 0,030998 & 0,009381 \\
P.M. & 0,005714 & 0,109675 & 0,064719 & $-0,22375$ & 0,114258 & $-0,24561$ \\
Doen. & $-0,17011$ & $-0,01386$ & 0,043466 & $-0,15975$ & $-0,0928$ & 0,001401 \\
Oco & $-0,07332$ & 0,064436 & 0,000441 & $-0,05528$ & 0,035612 & $-0,00191$ \\
Reen. & $0,954222^{*}$ & $-0,01759$ & $-0,00167$ & 0,064341 & $-0,03206$ & 0,001095 \\
Esp. Ad. & $-0,13495$ & $-0,07821$ & $-0,20702$ & 0,014753 & 0,007921 & $-0,001$ \\
Esp. In. & 0,055879 & 0,108243 & 0,110803 & $-0,07172$ & $-0,11467$ & 0,001094 \\
Esp. Rest. & 0,09544 & 0,001666 & 0,128673 & 0,035964 & 0,073163 & 0,000225 \\
Duas Árv. & 0,032023 & 0,11815 & $-0,04138$ & 0,044563 & $-0,95251^{*}$ & $-0,0009$ \\
Variância & 0,997719 & 1,020348 & 0,996805 & 1,003216 & 1,003517 & 0,11762 \\
explicada & & & & & & \\
Prp.Totl & 0,071266 & 0,072882 & 0,0712 & 0,071658 & 0,07168 & 0,008401 \\
\hline CP - Componente principal & & & & &
\end{tabular}

Observa-se nesta tabela que o primeiro componente expressa um contraste entre poda leve e média. O segundo está expressando o atributo doença, o terceiro espaço inadequado, o quarto um contraste entre espaçamento adequado e restrito ao tronco, o quinto expressa poda drástica e o sexto o atributo rachadura.

Desses componentes, os seis primeiros apresentaram autovalores superiores a 1. Além desses, na seqüência, foram escolhidos entre os sete componentes restantes, os componentes sete e dez, que foram interpretados como expressando, respectivamente, a presença de oco no tronco das árvores e a análise externa do tronco. Estes componentes foram considerados como os mais importantes, entre os sete componentes restantes, do ponto de vista de causas de uma possível presença 
de cupins nas árvores. A Tabela 5 mostra os autovalores e as respectivas variâncias para os componentes extraídos e os selecionados para a análise de regressão.

Os oito componentes selecionados para a análise de regressão, conforme Tabela 5 que apresentam asterisco, explicaram $84 \%$ da variação total dos dados originais, o que foi considerado como aceitável. Observa-se, portanto, que da aplicação de componentes principais resultou, como era de se esperar, em uma redução da dimensionalidade dos dados, passando de 14 variáveis independentes, para oito componentes principais.

Tabela 5. Autovalores e variâncias dos componentes principais.

\begin{tabular}{cccc}
\hline $\begin{array}{c}\text { Componentes } \\
\text { Principais }\end{array}$ & Autovalores & $\begin{array}{c}\text { \% Variância } \\
\text { explicada }\end{array}$ & $\begin{array}{c}\% \\
\text { Acumulada }\end{array}$ \\
\hline 1 & $3,022027^{(1)}$ & 21,6 & 21,6 \\
2 & $2,036182^{(1)}$ & 14,5 & 36,1 \\
3 & $1,598098^{(1)}$ & 11,4 & 47,5 \\
4 & $1,47229^{(1)}$ & 10,5 & 58,1 \\
5 & $1,167469^{(1)}$ & 8,3 & 66,4 \\
6 & $1,045491^{(1)}$ & 7,5 & 73,9 \\
7 & $0,925966^{(1)}$ & 6,6 & 80,5 \\
8 & $0,802551^{(1)}$ & 5,7 & 86,2 \\
9 & 0,631836 & 4,5 & 90,7 \\
10 & $0,486375^{(1)}$ & 3,5 & 94,2 \\
11 & 0,367789 & 2,6 & 96,8 \\
12 & 0,340222 & 2,43 & 99,3 \\
13 & 0,103704 & 0,7 & 100 \\
(1) Componentes principais selecionados. &
\end{tabular}

\subsection{Análise de Regressão}

O processo de cálculo dos coeficientes da equação de regressão entre as variáveis dependentes Prospecção interna - Prosp. Int. e Análise Interna - An. Int., e as variáveis independentes, foi feito através da seguinte seqüência de cálculos matriciais (Jolliffe, 1986): 


$$
Z=X * A
$$

onde:

$\mathbf{Z}$ - indica o valor do k-ésimo componente principal para a i-ésima árvore;

$\mathbf{X}$ - matriz indicadora $(0,1)$;

A - matriz dos oito componentes principais da matriz de correlação (Tabela 5).

O modelo matemático genérico para análise de regressão é dado pela expressão:

$$
Y=X \beta+\delta
$$

onde:

Y - vetor de n observações da variável dependente;

$\mathbf{X}$ - matriz como (i,j)-ésimo elemento é o valor da j-ésima variável independente para a i-ésima observação;

$\beta$ - vetor dos coeficientes da regressão e

$\delta$ - vetor dos erros.

Tendo em vista que a matriz A dos componentes principais é ortogonal, o produto $\mathbf{X} \boldsymbol{\beta}$ pode ser escrito como XAA' $\boldsymbol{\beta}=\mathbf{Z} \boldsymbol{\gamma}$ onde $\boldsymbol{\gamma}=\mathbf{A}^{\prime} \boldsymbol{\beta}$. Assim, a equação geral de regressão (2) poderá ser escrita substituindo-se a matriz $\mathbf{X}$ pela de componentes principais $\mathbf{Z}$ e o valor $\beta$ por $\gamma$.

$$
\mathbf{Y}=\mathbf{Z} \gamma+\delta
$$

$\mathrm{Na}$ forma linear a expressão (3) para o caso presente onde foram selecionados oito componentes principais, é escrita como:

$$
\mathbf{Y}=\mathbf{A}+\gamma_{1} \mathbf{X}_{1}+\gamma_{2} \mathbf{X}_{2}+\gamma_{3} \mathbf{X}_{3}+\gamma_{4} \mathbf{X}_{4}+\gamma_{5} \mathbf{X}_{5}+\gamma_{6} \mathbf{X}_{6}+\gamma_{7} \mathbf{X}_{7}+\gamma_{8} \mathbf{X}_{8}+\delta
$$


Observa-se que na expressão (3), a matriz de variáveis independentes, foi substituída pela de componentes principais, representados pela matriz $\mathbf{Z}$, obtida pela expressão (1). Este procedimento constitui-se no processo de regressão por componentes principais.

Aplicando-se o método dos mínimos quadrados na expressão (3), separadamente para cada uma das variáveis dependentes Prospecção Interna e Análise Interna, calculou-se o vetor $\gamma$ composto pelas estimativas dos oito coeficientes da expressão (4) cujos valores são apresentados nas Tabelas 6 e 7, respectivamente, para Prospecção Interna (Prosp. Int.) e Análise Interna (An. Int.).

Tabela 6. Resultado da análise de regressão dos coeficientes dos componentes principais da Prospecção Interna.

\begin{tabular}{ccc}
\hline Coeficientes & $\gamma$ & $\begin{array}{c}\text { Erro Padrão } \\
\text { de } \gamma\end{array}$ \\
\hline $\mathrm{A}$ & 0,282629 & 0,081492 \\
$\gamma_{1}$ & $-0,07976$ & 0,110484 \\
$\gamma_{2}$ & 0,111043 & 0,158061 \\
$\gamma_{3}$ & 0,098811 & 0,143062 \\
$\gamma_{4}$ & $-0,23285$ & 0,114248 \\
$\gamma_{5}$ & $-0,60094$ & 0,254075 \\
$\gamma_{6}$ & $-0,13986$ & 0,204509 \\
$\gamma_{7}$ & $-0,03554$ & 0,168824 \\
$\gamma_{8}$ & 0,127375 & 0,204789 \\
\hline
\end{tabular}

As estatísticas obtidas da análise correspondentes ao modelo da variável dependente Prosp. Int. foram as seguintes:

a) Coeficiente de correlação múltipla: $R=0,65$

b) Coeficiente de determinação: $R^{2}=0,42$

c) Probabilidade de significância do modelo: 0,00279.

Portanto o modelo é significante tanto ao nível de $5 \%$ como de $1 \%$ de níveis de significância. 
Tabela 7. Resultado da análise de regressão dos coeficientes dos componentes principais da Análise Interna.

\begin{tabular}{ccc}
\hline Coeficientes & $\gamma$ & $\begin{array}{c}\text { Erro Padrão } \\
\text { de } \gamma\end{array}$ \\
\hline $\mathrm{A}$ & 0,016416 & 0,063035 \\
$\gamma_{1}$ & $-0,01334$ & 0,085461 \\
$\gamma_{2}$ & $-0,13579$ & 0,122262 \\
$\gamma_{3}$ & 0,136746 & 0,11066 \\
$\gamma_{4}$ & 0,016331 & 0,088372 \\
$\gamma_{5}$ & 0,112954 & 0,19653 \\
$\gamma_{6}$ & $-0,05897$ & 0,15819 \\
$\gamma_{7}$ & $-0,27521$ & 0,130587 \\
$\gamma_{8}$ & 0,431207 & 0,158407 \\
\hline
\end{tabular}

Para o modelo da variável dependente An. Int., as estatísticas obtidas da análise foram as seguintes:

a) Coeficiente de correlação múltipla: $R=0,67$

b) Coeficiente de determinação: $R^{2}=0,44$

c) Probabilidade de significância do modelo: 0,00152.

Portanto, da mesma forma que o modelo anterior, este é também significante tanto a 5 \% como a 1 \% de níveis de significância.

Multiplicando-se o vetor $\gamma$ pela matriz A dos oito componentes principais selecionados, obtém-se o vetor dos quatorze coeficientes dos modelos de regressão múltiplas que se procuram, através da expressão:

$$
\hat{\beta}=\hat{A} \gamma
$$

As Tabelas 8 e 9 apresentam, respectivamente, para as variáveis dependentes Prosp. Int. e An. Int., os resultados obtidos pela aplicação da expressão (5). 
Tabela 8. Coeficientes para o modelo completo da Prospecção Interna:

\begin{tabular}{ll}
\hline \multicolumn{1}{c}{ Variáveis } & \multicolumn{1}{c}{ Coeficientes } \\
\hline An. Ext. & $0,229134^{(1)}$ \\
Sad. & 0,03647 \\
Fer. & 0,055729 \\
Rach. & $0,094591^{(1)}$ \\
P.L. & $-0,19311^{(1)}$ \\
P.D. & $0,551111^{(1)}$ \\
P.M. & $-0,03754^{(1)}$ \\
Doen. & $0,106882^{(1)}$ \\
Oco & 0,047479 \\
Reen. & $0,090172^{(1)}$ \\
Esp. Ad. & $-0,18917^{(1)}$ \\
Esp. In. & $-0,0411$ \\
Esp. Rest. & $0,218237^{(1)}$ \\
Duas Arv. & $-0,06249$ \\
(1) Modelo simplificado. &
\end{tabular}

Tabela 9. Coeficientes para o modelo completo da Análise Interna:

\begin{tabular}{ll}
\hline \multicolumn{1}{c}{ Variáveis } & \multicolumn{1}{c}{ Coeficientes } \\
\hline An. Ext. & $0,374881^{(1)}$ \\
Sad. & 0,011016 \\
Fer. & 0,009907 \\
Rach. & 0,064563 \\
P. L. & $-0,02967$ \\
P. D. & $-0,09902$ \\
P. M. & 0,078507 \\
Doen. & $-0,08575$ \\
Oco & $0,275786^{(1)}$ \\
Reen. & $-0,0246$ \\
Esp. Ad. & $-0,05762$ \\
Esp. In. & $-0,08582$ \\
Esp. Rest. & $0,118306^{(1)}$ \\
Duas Arv. & $-0,05953$ \\
\hline
\end{tabular}

(1) Modelo simplificado. 


\section{REFERÊNCIAS BIBLIOGRÁFICAS}

ABBUD, B. Eletropaulo troca árvores para preservar rede. O Estado de São Paulo. Cidades, São Paulo, 26 set. 1999. p.C-4.

ADAMSON, A.M. Termites and the fertility of soils. Tropical Agriculture, v.20, n. 6, p.107-112, 1943.

BARCELOS, P.R.A. A dendrocirurgia. In: CURSO SOBRE MANEJO DA ARBORIZAÇÃO URBANA E DENDROCIRURGIA, Jaboticabal, 2000. Jaboticabal: Funep, 2000. p.1-14.

BARRETT, D.K.; SEABY, D.A.; GOURLAY, I.D. Portable "compression strength meter"; a tool for the detection and quantification of decay in trees. Arboricultural Journal, v.11, p.313-322, 1987.

BETHGE, K.; MATTHECK, C.; HUNGER, E. Equipment for detection and evaluation of incipient decay in trees. Arboricultural Journal, v.20, p.13-37, 1996.

BECKER, G. Coptotermes in the heartwood of Living trees in Central and West Africa. Material und Organismen, v.10, p.149-154, 1975.

CATENA, G.; PALLA, L.; CATALANO, M. Thermal infrared detection of cavities in trees. European Journal of Forest Pathology,. v.20, p.201-210, 1990.

CHANTRE, G.; ROZENBERG, P. Can drill resistance profiles (Resistograph) lead to within-profile and within-ring density parameters in Douglas fir wood? In: CTIA/IUFRO INTERNATIONAL WOOD QUALITY WORKSHOP, 1997. Timber management toward wood quality and end-product value. p.41-46.

CONSTANTINO,R. Identificação de cupins. Constant@unb.br (10 Out. 2001).

CONSTANTINO,R. http://www.unb.br/ib/zoo/docente/constant/catal/catnew.html (07 Jan. 2002).

COOPER, P.A. Investigation of subterranean termite activity in trees in Toronto, Ontario. In: ANNUAL MEETING OF THE CANADIAN WOOD PRESERVATION ASSOCIATION, 5., Vancouver, 1984. Proceedings. p.60-61. 
COOPER, P.A.; GRACE, J.K. Association of the eastern subterranean termite, Reticulitermes flavipes (Kollar) (Isoptera: Rhinotermitidae), with living trees in Canada. Journal of Entomological Science, v.22, n.4, p.353-354, Oct. 1987.

DOLWIN, J.A. Evaluation of internal defects in trees and the legal implications. Arboricultural Journal, v.20, p.173-178, 1996.

DOLWIN, J.A.; LONSDALE, D.; BARNETT, J. Detection of decay in trees. Commonwealth Forestry Review, v.77, n.4, p.277-280, 1998.

DYKEMA, P. The resistograph.

http://www.urban-forestry.com/citytrees/v37n1a18.html (13 Nov. 2001).

FONTES, L.R.; MAURO, M.R.; BERTI FILHO, E.; MARTINS, V.G. Cupim do cerne, Coptotermes havilandi, praga da arborização urbana em São Paulo. In: CONGRESSO BRASILEIRO DE ENTOMOLOGIA, 16., ENCONTRO NACIONAL DE FITOSSANITARISTAS, 7., Salvador, 1997. Resumos. Salvador: Sociedade Entomológica do Brasil / EMBRAPA-CNPMF, 1997. p.277.

FONTES, L.R. Considerações sobre a complexidade da interação entre o cupim subterrâneo, Coptotermes havilandi, e a arborização no ambiente urbano. In: FONTES, L.R.; BERTI FILHO, E. Cupins: o desafio do conhecimento. Piracicaba: FEALQ, 1998. p.109-124.

FONTES, L.R; ARAUJO, R.L. Os cupins. In: MARICONI, F.A.M. (Coord.) Insetos e outros invasores de residências. Piracicaba: FEALQ, 1999. p.35-90.

FREYTAG, E.D.; CINK, J.H. Field trials with premise (imidacloprid) termiticide for controlling formosan subterranean termites in trees in New Orleans, Louisiana. In: INTERNATIONAL SYMPOSIUM ON COPTOTERMES FORMOSANUS IN NEW ORLEANS, 2., Louisiana, 2001. Resumos. New Orleans: U.S. Department of Agriculture, 2001. p.23.

GAY, F.J. A case of house infestation by a tree-dwelling colony of Coptotermes frenchi Hill. Journal of the Council for Scientific and Industrial Research, v.19, p.330334, 1946.

GOYA, C.R.Y. Relato histórico da arborização na cidade de São Paulo. In: CONGRESSO BRASILEIRO SOBRE ARBORIZAÇÃO URBANA, 1., ENCONTRO NACIONAL SOBRE ARBORIZAÇÃO URBANA, 4., Vitória, 1992. Anais. Vitória: Prefeitura Municipal de Vitória, 1992. p.403-408.

GRUBER, F. Measurement results on the identification of red hearts of European beech (Fagus sylvatica L.) with the drill devices Teredo and Resistograph 1410 and also the impulse hammer sound system IML. Allgemeine. Forst und Jagdzeitung, v.171, n.7, p.117-123, 2000. 
HABERMEHL, A. A new non-destructive method for determining internal wood condition and decay in living trees. Part I. Principles, method and apparatus. Arboricultural Journal, v.6, p.1-8, 1982.

HABERMEHL, A.; RIDDER, H.W. Computerised tomographic investigations of street and park trees. Arboricultural Journal, v.19, p. 419-437, 1995.

HAGEN, H.A. White ants destroying living trees and changing the foliage, in Cambridge, Mass. The Canadian Entomologist, v.17, p.134-136, 1885.

HARRIS, W.V. Termites and forestry. Empire Forestry Review, v. 34, p.160-166, 1955.

HARRIS, W.V. Termites: their recognition and control. 2.ed. London: Longman, 1971. 180p.

HENDERSON, G.; SHARPE, K.; FELIX, J. Sufluramid baiting of termite infested trees in New Orleans: a preliminary report. Baton Rouge: Louisiana State University Agricultural Center, Department of Entomology. 1995.

HETRICK, L.A. Kalotermes approximatus snyder infests roseaceous trees (Isoptera: Kalotermitidae). The Florida Entomologist, v.44, n. 1, p.53-54. 1953.

HICKIN, N.E. Termites: a world problem. London: Hutchinson, 1971. 232p.

HOMEM, M.C.N. Higienópolis, grandeza e decadência de um bairro paulistano. São Paulo: Departamento do Patrimônio Histórico da Secretaria Municipal de Cultura, 1980. 183p. (Série História dos Bairros de São Paulo, 17).

INSTITUTO CULTURAL ITAÚ. Cadernos Cidade de São Paulo: Bairro de Higienópolis. São Paulo: ICI, 1996. 34p.

JOLLIFFE, I.T. Principal component analysis. springer series in statistics. New York: Springer-Verlag, 1986. 271p.

JUTTNER, A.S. Formosan termites in trees, part II. Arborage. http://www.arborage.com (Nov. 1997). p.36-40.

KALSHOVEN, L.G.E. Observations on Coptotermes havilandi Holmgr. (Javanicus Kemn.) (Isoptera). Beaufortia. Zoological Museum, v.9, n.101, p.121-137, May 1962.

KALSHOVEN, L.G.E. Coptotermes curvignathus causing the death of trees in Indonesia and Malaya. Entomologische Berichten, v.23, p.90-100, 1963.

KOFOID, C.A. (Ed.) Termites and termite control. 2.ed. Berkeley: University of California Press, 1934. 795p. 
LAI, P.Y.; TAMASHIRO, M.; YATES, J.R.; SU, N.Y.; FUJI, J.K.; EBESU, R.H. Living plants in Hawaii attacked by Coptotermes formosanus. Proceedings of the Hawaiian Entomological Society, v.24, n.2-3, p.283-286, Oct. 1983.

LELIS, A.T. Problemas causados por cupins em edificações. In: SIMPÓSIO BRASILEIRO DE ENTOMOLOGIA URBANA,1.; CONGRESSO BRASILEIRO DE ZOOLOGIA,21., Campinas, 1985. Anais. Campinas: Universidade Estadual de Campinas, 1985. p.1-5.

LELIS, A.T. Termite problem in São Paulo city - Brazil. In: CONGRESS OF THE INTERNATIONAL UNION FOR THE STUDY OF SOCIAL INSECTS (IUSSI),12., Paris, 1994. Resumos. Paris: IUSSI, 1994. p.253.

LEONARDO, A.M.C.; BARSOTTI, R.C. Swarming and incipient colonies of Coptotermes havilandi (Isoptera, Rhinotermitidae). Sociobiology, v.31, n.1, p.131$142,1998$.

LEONARDO, A.M.C.; BARSOTTI, R.C.; DIETRICH, C.R.R.C. Review and update on the biology of Coptotermes havilandi (Isoptera, Rhinotermitidae). Sociobiology, v.33, n.3, p.339-356, 1999.

MATTHECK, C.; BRELOER, $H$. Field guide for visual tree assessment (VTA). Arboricultural Journal, v.18, p.1-23, 1994.

MATTHECK, C.; BRELOER, $H$. The body language of trees: a handbook for failure analysis. London: The Stationery Office, 1997. 239p. (Research for Amenity Trees, 4).

MATHEWS, A.G.A Studies on termites from the Mato Grosso State, Brazil. Rio de Janeiro: Academia Brasileira de Ciências. 1977. 267p.

MELLO FILHO, L.E. Arborização urbana. In: ENCONTRO NACIONAL SOBRE ARBORIZAÇÃO URBANA, 1., Porto Alegre, 1985. Anais. Porto Alegre: Secretaria Municipal do Meio Ambiente, 1985. p.117-127.

MESSENGER, M. Informations about Resistograph ${ }^{\circledR}$ and termites in trees. mmesseng@usa.net (05 Apr. 2001).

MILANO, M.S. Avaliação quali-quantitativa e manejo da arborização urbana: exemplo de Maringá - PR. Curitiba, 1988. 120p. Tese (Doutorado) - Universidade do Paraná.

NICOLOTTI, G.; MIGLIETTA, P. Using high-technology instruments to assess defects in trees. Journal of Arboriculture, v.24, n.6, p.297-302, Nov. 1998.

NOVARETTI, W.R.T.; FONTES, L.R. Cupins: uma grave ameaça àcana-de-açúcar no nordeste do Brasil. In: FONTES, L.R.; BERTI FILHO, E. Cupins: o desafio do conhecimento. Piracicaba: FEALQ, 1998. p.163-172. 
OLIVEIRA, A.M.F.; LELIS, A.T.; LEPAGE, E.S.; LOPEZ, G.A.C.; OLIVEIRA, L.C.S.; CAÑEDO, M.D.; MILANO, S. Agentes destruidores da madeira. In: LEPAGE, E.S. (Coord.) Manual de preservação de madeiras. São Paulo: IPT/SICCT, 1986. v.1, n.1637, cap.5, p.99-278.

OSBRINK, W.L.A.; WOODSON, W.D.; LAX, A.R. Population of formosan subterranean termite, Coptotermes formosanus (Isoptera: Rhinotermitidae), estabilished in living trees in New Orleans, Louisiana, U.S.A. In: INTERNATIONAL CONFERENCE ON URBAN PESTS, 3., Prague, 1999. Proceedings. Prague: Czech University of Agriculture Prague, 1999. p.341-345.

PANTEM, E. Eletropaulo troca árvores para preservar rede. O Estado de São Paulo. Cidades, São Paulo, 26 set. 1999. p.C-4.

PERRY, D.H.; LENZ, M.; WATSON, J.A.L. Relationships between fire, fungal rots and termite damage in Australian forest trees. Australian Forestry, v.48, n.1, p.46-53, 1985.

REUTER, M.C. Evaluation of non-destructive testing methods for timber quality assessment on standing trees in mixed hill dipterocarp forests in Sarawak, Malaysia. Hamburg, 2000. 107p. Thesis (Academic Degree) - University of Hamburg.

RHOADS, A.F.; MEYER, P.W.; JEFFRIES, H.A. Termites threaten city trees. Journal of Arboriculture, v.5, n.7, p.162-163, July 1979.

RICKLEFS, R.E,A. Economia da natureza. 3.ed. Rio de Janeiro: Guanabara Koogan, 1996. 470p.

RINN, F.; SCHWEINGRUBER, F.-H.; SCHÄR, E. Resistograph and X-Ray density charts of wood comparative evaluation of drill resistance profile and X-ray density charts of different wood species. Holzforschung, v.50, n.4, p.303-311, 1996.

SÂO PAULO. Secretaria Municipal de Planejamento. Vegetação significativa do município de São Paulo. São Paulo, 1998. p.101-398 (Série Documentos).

SEABY, D.A. Recent advances in detection of wood decay. Forest Commission Bulletin, v.97, n.21, p.168-176, 1990.

TAKAHASHI, L.Y.; DALCIN, E.C. A informática no inventário e monitoramento da arborização urbana. In: CONGRESSO BRASILEIRO DE ARBORIZAÇÃO URBANA, 2., ENCONTRO NACIONAL SOBRE ARBORIZAÇÃO URBANA, 5., São Luis, 1994. Anais. 1994. p.201-206.

VEIGA, A.A Glossário em dasonomia. 3.ed. São Paulo: Secretaria de Agricultura e Abastecimento, 1983. 118p. (Publicação IF, 4). 
WILCKEN, C.F.; RAETANO, C.G. Controle de cupins em florestas. In: BERTI FILHO, E.; FONTES, L.R. Alguns aspectos atuais da biologia e controle de cupins. Piracicaba: FEALQ, 1995. p.141-154.

ZORZENON, F.J.; POTENZA, M.R. Cupins: pragas em áreas urbanas. São Paulo: IB, 1998. 40p. (IB. Boletim Técnico, 10). 